
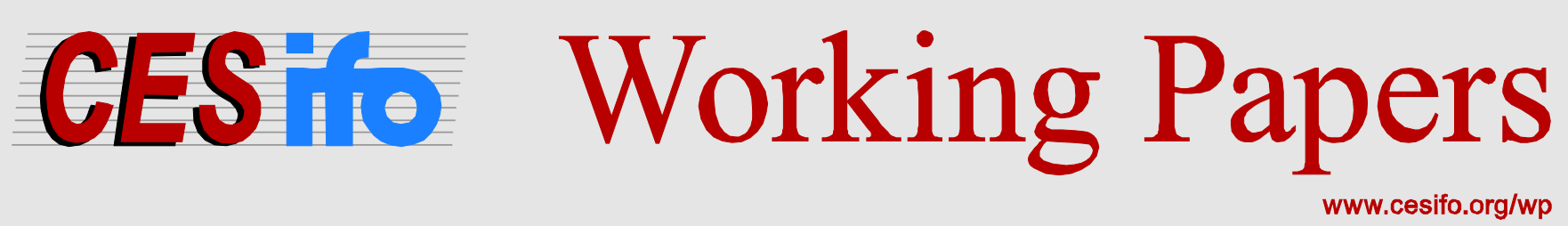

\title{
More Schooling, More Children? Compulsory Schooling and Fertility in Europe
}

\author{
Margherita Fort \\ Nicole Schneeweis \\ Rudolf Winter-Ebmer
}
CESIFO WORKING PAPER NO. 5068
CATEGORY 5: ECONOMICS OF EDUCATION
NOVEMBER 2014
An electronic version of the paper may be downloaded
- from the SSRN website: Www.SSRN.com
- from the RePEc website: Www.RePEc.org
- from the CESifo website: $\quad$ www.CESifo-group.org/wp




\title{
More Schooling, More Children? Compulsory Schooling and Fertility in Europe
}

\begin{abstract}
We study the relationship between education and fertility, exploiting compulsory schooling reforms in England and Continental Europe, implemented between 1936 and 1975. We assess the causal effect of education on the number of biological children and the incidence of childlessness. We find surprising results for Continental Europe: the additional education generated by compulsory schooling expansions led to an increase in the number of biological children per woman and a decrease in childlessness. The results for England point in the opposite direction. Moreover, for the Continent we find that education during this time led to fewer women who remained unmarried over their life course. Our findings are robust to a number of sensitivity and falsification checks.
\end{abstract}

JEL-Code: I200, J130.

Keywords: education, fertility, causal effects.

\author{
Margherita Fort \\ University of Bologna \\ Department of Economics \\ Piazza Scaravilli 2 \\ Italy-40100 Bologna \\ margherita.fort@unibo.it
}

\author{
Nicole Schneeweis \\ Johannes Kepler University \\ Department of Economics \\ Altenbergerstr. 69 \\ Austria-4040 Linz \\ nicole.schneeweis@jku.at
}

\author{
Rudolf Winter-Ebmer \\ Johannes Kepler University \\ Department of Economics \\ Altenbergerstr. 69 \\ Austria-4040 Linz \\ rudolf.winterebmer@jku.at
}

October 20, 2014

Fort: also affiliated with CESIFO and IZA and was affiliated with CHILD in the early stages of this project. Schneeweis: also affiliated with IZA and CEPR. Winter-Ebmer: also affiliated with the IHS, CReAM, IZA and CEPR. We would like to thank D. Card, C. Dustmann, B. Fitzenberger, R. Riphahn, G. Weber, B. Hart, E. Moretti as well as seminar participants in Amsterdam, Freiburg, Stirling, Padova, Bologna, Milano, Alghero, Vienna, Mannheim, UC Berkeley, UC Davis and RES Cambridge. We would like to thank the Austrian FWF for funding of the "The Austrian Center for Labor Economics and the Analysis of the Welfare State". M. Fort acknowledges financial support from MIUR- FIRB 2008 project RBFR089QQC-003-J31J10000060001. N. Schneeweis acknowledges support from UC Berkeley for hospitality. The SHARE data collection has been primarily funded by the EC through the 5th, 6th and 7th framework programme the U.S. National Institute of Aging (NIA) and other national Funds (in Austria the Ministries of Science and Labor). The ELSA data were made available through the UK Data Archive (UKDA). The funding is provided by the U.S. NIA, and a consortium of UK government departments coordinated by the Office for National Statistics. We dedicate this paper to Anita, who was born during the revision phase of this paper. 


\section{Introduction}

Conventional wisdom on fertility rates tells us that more education reduces fertility. Skirbekk (2008) provides a meta-study on the correlation of social status, wealth, education and fertility: while in previous centuries higher social status was positively correlated with the number of children, this relation shifted to a negative or neutral one in the last century. Only since the beginning of the 20th century, data on education became available: out of 528 samples, in more than 88 percent the higher educated group had lower average fertility. While fertility generally has dropped in most developed countries, the fertility gap between high and low educated women has not converged (Skirbekk, 2008, p. 160). The situation is similar in developing countries (Martin, 1995; Strauss and Thomas, 1995).

These correlations do not necessarily imply a causal relationship running from education to fertility; they may instead be due to reversed causality or third factor problems. Early pregnancies might impede further education or school drop-outs might also have a personality prone to early motherhood. While in the surveys above no causal papers were included, available causal studies relying on compulsory schooling reforms do not show a clear picture. Most studies find that education reduces teenage-childbearing and postpones motherhood but the evidence on the effect of education on total fertility is ambiguous.

Studying the impact of education on fertility is important to get a complete picture of the non-pecuniary effects of education (Oreopoulos and Salvanes, 2011). Moreover, given the strong genetic or social intergenerational correlation in education and social status, a socio-economic gradient in fertility patterns will have long-term impacts on the educational and social structure of the population in years to come; which may, in turn, have economic and social repercussions.

This paper brings a new and convincing look to an old topic which has been overwhelmingly answered (mostly) by demographers in the negative: this literature takes it for granted that more education reduces fertility. Combining data from two panel surveys, SHARE (Survey on Health, Ageing and Retirement in Europe) and ELSA (English Longitudinal Study of Ageing), and information on mandatory schooling reforms between 
1936 and 1975 in England and Continental Europe, we provide robust empirical evidence that the additional female education due to compulsory schooling expansions increased fertility and reduced childlessness in Continental Europe. For England, we find a negative impact on fertility and a positive impact on childlessness.

We interpret our estimates as Local Average Treatment Effects and characterize the women to whom our estimates apply. The compliers in our study turn out to have poorer parental background and grew up in larger families, i.e. might be more family-oriented, compared to the average individual in our sample. While this is true for both, England and Continental Europe, these characteristics are more pronounced in Continental Europe.

Moreover, we complement our findings with a detailed analysis of the potential channels that may drive our results, in particular the marriage market. While this evidence is crucial for the understanding of the empirical findings obtained, these aspects are often neglected in previous papers that address the same issue using comparable identification strategies. Our findings for the marriage market are in line with the results obtained for fertility. For Continental Europe, we find that women with more education are less likely to remain unmarried over their life-course. On the contrary, in England, we find a negative effect on the probability of marriage, either current or previous marriages.

These novel effects of education on fertility are also compatible with the view that children are a normal good, education increases wages of females and of their spouses on the labor market and, that the income effect on the labor market dominates the substitution effect. Regarding social values, the position of women in society and family orientation in Europe in the mid of the 20th century, these considerations are not implausible.

This paper is organized as follows. Section 2 discusses the relationship between education and fertility as well as marriage behavior and reviews the relevant literature. Sections 3 and 4 describe our empirical strategy and the data. Section 5 presents the baseline estimates, discusses the interpretation of our results and investigates potential channels through which education might influence fertility. Finally, section 6 provides sensitivity and falsification tests and section 7 concludes. 


\section{Education and fertility}

There are several ways how economists think about the relationship between education and fertility. The first channel is labor supply (Becker, 1965). Education increases the earnings capacity, thus the opportunity costs of leaving the labor market to have and raise children. This substitution effect predicts a decrease in fertility. On the other hand, higher permanent income increases fertility if children are normal goods. The strength of this income effect might be weakened by a quantity-quality trade-off in children (Becker and Lewis, 1973), i.e. due to higher income parents tend to invest more in the quality of their children, not the quantity. ${ }^{1}$ Depending on the magnitudes of the substitution and the income effect, both a positive and a negative relationship between education and fertility are possible.

Next to labor supply, more education may render females more attractive on the marriage market, thus increasing their marriage chances. Improved general and professional knowledge and the enhanced strength in personality should make individuals more openminded, flexible and mobile, which in turn should increase their chances to find an appropriate partner. $^{2}$ This will increase fertility. Moreover, additional education may boost the educational attainment and income of the potential partner (Behrman and Rosenzweig, 2002) through assortative mating. Depending on males' involvement in child-rearing activities, increased spousal earnings might again induce a substitution and an income effect on the labor market. In times or in countries, where mainly women are responsible for child-care, the income effect might strongly dominate the substitution effect of husbands, which should also increase fertility. Overall, the effects from the marriage market tend to increase fertility.

Moreover, education may improve information and decision making on contraceptive use (Thomas, Strauss and Henriques, 1991) and may increase female's bargaining power within a marriage. Finally, staying longer in school might, in principle, reduce the repro-

\footnotetext{
${ }^{1}$ Recent studies on female employment rates, unemployment and fertility (Adsera, 2005; Ahn and Mira, 2002; Dehejia and Lleras-Muney, 2004; Del Bono et al., forthcoming) question the preponderance of the substitution effect and find pro-cyclical fertility in developed countries.

${ }^{2}$ Contrary effects may be possible, i.e. that highly qualified women face more difficulties on the marriage market because men tend to "marry down" (Rose, 2003).
} 
ductive life of females, if fertility rates during formal education are lower than afterwards. However, even negative effects of additional education on teen fertility may be consistent with negligible (or positive) completed fertility effects, if there are positive catch-up effects beyond the teenage years (Fort, 2009; Geruso and Royer, 2014).

Several recent studies investigated the relationship between education and fertility using compulsory schooling reforms to instrument for years of schooling. Most of the papers that use European data, focus on single countries. Monstad, Propper and Salvanes (2008) studied completed fertility and timing of births in Norway, Fort (2009) investigated Italy, Braakmann (2011) and Geruso and Royer (2014) looked at the United Kingdom and Cygan-Rehm and Maeder (2013) examined Germany. Monstad et al. (2008), Fort (2009) and Geruso and Royer (2014) find evidence of a postponement of childbearing away from the teenage years, but no significant effects on total fertility. Similarly, Kirdar, Dayioglu Tayfur and Koc (2011) find that the compulsory schooling reform in Turkey lead to motherhood postponement. Conversely, Braakmann (2011) detects a positive causal effect of education on the number of children and Cygan-Rehm and Maeder (2013) find a negative effect on the number of children and a positive effect on childlessness.

For the United States, three further studies present contradictory evidence: Leon (2004) uses compulsory schooling laws and shows that education causally reduces fertility. McCrary and Royer (2011), on the other hand, use age at school entry as an instrumental variable for education and find no effects in two American states, California and Texas. Duflo, Dupas and Kremer (2010) argue that such an experiment is different from extending schooling because here children typically drop out at the same age, but some start schooling earlier. Therefore, school extension experiments might have impacted fertility differently due to the fact that young females are longer in school during teenage years. Moreover, Amin and Behrman (2014) studied the Minnesota twin registry. Their withintwin estimates show that more educated twins tend to have fewer children but show the same probability of being childless. This paper differs from the compulsory schooling studies, since the estimates apply to a different group of females. The twins have on average more than 13 years of schooling and are therefore not comparable to compliers to com- 
pulsory schooling laws, who tend to come from the bottom of the education distribution (Brunello et al., 2009).

Black, Devereux and Salvanes (2008) investigated the direct effect of the change in mandatory schooling legislation in Norway and in the U.S. on the timing of births and found a reduction in teenage-births due to the increase in compulsory education.

In short, while most studies across different countries suggest that education leads to motherhood postponement, the empirical evidence on the effect of education on total fertility is inconclusive: the results obtained vary substantially, with some authors finding no significant relationships, while others obtaining positive or negative effects.

There are some studies on the causal impact of education on the marriage market, which is one important route by which fertility effects of education could be channeled. Currie and Moretti (2003) use college openings in the U.S. to identify the causal impact of maternal education on marriage probabilities and find a positive impact. As the authors concentrate on child outcomes, they have only a sample of women with children. Furthermore, their IV estimates are based on compliers that may be different to those affected by compulsory schooling reforms.

Leon (2004) uses compulsory schooling reforms in the U.S. and finds positive, although insignificant effects of education on marriage. Fort (2009) finds no effects of education on the timing of first marriages in Italy. Lefgren and McIntyre (2006) - using U.S. Census data and instrumenting education by quarter of birth - find positive causal effects of females' education on husbands' earnings, but no effects on the probability of marriage. The same results have been obtained by Anderberg and Zhu (2014) for England and Wales using month of birth to instrument for educational qualifications. Similarly, no significant effects on husbands' employment status or years of education and the probability of marriage are obtained by Braakmann (2011) for the UK and Cygan-Rehm and Maeder (2013) for Germany. Geruso and Royer (2014) also investigate the husbands' education and age and found positive effects on these variables.

In this study, we use compulsory schooling reforms in Europe to instrument for years of education, a strategy which has been used by Brunello, Fort and Weber (2009) to 
investigate the returns to schooling in Europe, Brunello, Fabbri and Fort (2013) to study the effect of education on obesity and Schneeweis, Skirbekk and Winter-Ebmer (2014) to analyze long-term effects of schooling on cognitive performance.

\section{Empirical strategy}

We use the exogenous variation in schooling induced by mandatory schooling reforms to identify the causal effect of education on fertility. The use of school entry age laws or minimum school leaving age laws as instruments for educational attainment was firstly introduced by Angrist and Krueger (1991) and is now widespread in the literature. As in previous studies, the key assumption we make to guarantee causal interpretation of our estimates is that, within each country and reform, additional schooling was assigned to women only on the basis of their date of birth and independently of their future fertility choices.

As in previous studies exploiting educational reforms in Europe, we use schooling reforms which affected the individuals' years of schooling at roughly the same education level, i.e. secondary education (either ISCED 2 or ISCED 3, depending on the specific reform considered). We use data from the Survey of Health, Ageing and Retirement in Europe (SHARE) and the English Longitudinal Study of Ageing (ELSA), panel studies that survey representative samples of individuals aged 50 and above in several European countries. Based on the available data and the nature of the various education reforms that have been implemented, we selected the following reforms for our study: England 1947, Austria 1962/66, Denmark 1958, Denmark 1971, France 1936, France 1959/67, Italy 1963, Netherlands 1950 and Netherlands 1971/75. ${ }^{3}$

Table 1 lists the countries and reforms we consider, presenting the change in years of education prescribed by the law, the change in the resulting school leaving age and

\footnotetext{
${ }^{3}$ Due to data limitations, we do not use very early reforms (Belgium 1914/19) or very late reforms (Belgium 1983, England 1972). We further drop countries in which the reforms have been implemented gradually (Germany, Sweden and Switzerland), countries that experienced short term reductions in compulsory schooling (Czech Republic, Greece) and countries in which the reform expanded compulsory schooling by reducing the school entry age (Poland). We further dropped the reform in Spain in 1970 due to a very weak first stage estimate.
} 
the pivotal cohort, i.e. the first cohort potentially affected by the reform. The reforms considered range from 1-year to 3-year extensions in compulsory schooling duration. For a short description of each reform and the explanation of the choice of the pivotal cohort see Appendix A.1.

Pooling over all reforms our instrument exhibits variation over cohorts within each country and across countries for any given cohort. The variability over both, cohorts and countries allows us to control for country-reform fixed effects as well as cohort fixed effects, which we assume invariant across countries, while we capture the trends in fertility and other unobserved characteristics across cohorts in any single country with country-reformspecific polynomials that differ before and after each reform. ${ }^{4}$ We estimate equations (1) and (2):

$$
\begin{gathered}
Y_{i r k}=\beta_{0}+\beta_{1} E_{d u_{i r k}}+\beta_{2} \mathbf{X}_{i r k}+\beta_{3} \text { Reform }_{r}+\beta_{4} \text { Cohort }_{k}+\beta_{5} T_{r k}+\beta_{6} \text { Tpost }_{r k}+\epsilon_{i r k} \\
E d u_{i r k}=\alpha_{0}+\alpha_{1} \text { Comp }_{r k}+\alpha_{2} \mathbf{X}_{i r k}+\alpha_{3} \text { Reform }_{r}+\alpha_{4} \text { Cohort }_{k}+\alpha_{5} T_{r k}+\alpha_{6} \text { Tpost }_{r k}+\mu_{i r k}
\end{gathered}
$$

where $Y_{i r k}$ is the dependent variable capturing fertility of individual $i$ in the countryreform $r$ of birth cohort $k ; E d u_{i r k}$ is the number of years of education; $\mathbf{X}_{i r k}$ is a vector of some control variables ${ }^{5} ;$ Reform $_{r}$ and Cohort $_{k}$ refer to country-reform and cohort fixed effects and $T_{r k}$ as well as Tpost $t_{r k}$ capture country-reform-specific linear trends in cohorts with an interaction for post reform cohorts. Since $\epsilon_{i r k}$ might be correlated with education, we estimate equation (1) with 2 SLS, instrumenting education with $C o m p_{r k}$, the compulsory years of schooling prescribed by the relevant reform, in the respective country and cohort. Equation (2) is the first stage equation.

Our instrumental variable is the number of mandatory schooling years given by law. In the pooled regressions, we assume that each additional mandatory year of education exerts the same effect on the actual number of years of schooling in all the countries included in the study. ${ }^{6}$

\footnotetext{
${ }^{4}$ Note that all fixed effects refer to a specific reform in a country, i. e. if we have two reforms within one country we control for each reform with a fixed effect and interact the trends for each reform. For the sake of brevity, we use the terms country and reform interchangeably when referring to fixed-effects.

${ }^{5} \mathrm{An}$ indicator for whether the individual is foreign born, whether a proxy respondent assisted during the interview or gave the full interview and indicators for interview-years.

${ }^{6}$ This is a plausible assumption. In the technical appendix, Brunello et al. (2009, Table B.2) review the evidence of mandatory schooling on average years of education based on single-country studies: the
} 
We account for trends in education and fertility using country-reform-specific linear trends that differ before and after each reform. These trends account for all the societal changes that either evolve slowly over time (like attitudes) or change at once (eg. the introduction of the pill or changes in divorce laws) but exert an influence on all women regardless of their cohort and age. Indeed, our identifying strategy relies on changes affecting cohorts differently before and after the schooling reforms, whereas other unobserved societal changes do never affect cohorts differently to a large extent and should be well captured by our country-reform-specific time trends.

Our identifying assumptions become more plausible when the width of the window around the pivotal cohort is small, i.e. when the comparison between individuals assigned to the new mandatory schooling obligations and those not assigned to the new regulations is local. Thus, we estimate our model using individuals born up to 10 years before/after the pivotal cohort (Sample 10) and up to 7 years before/after (Sample 7). As done by Battistin et al. (2009, p. 2216), we drop the pivotal cohorts themselves from the data: in most cases the pivotal birth cohort consists of individuals that are affected by the new regulations and individuals who are not affected, depending on their birth month, school-entry rules and the compliance to those rules.

While Brunello et al. (2009) and Brunello et al. (2013) used samples symmetric around the pivotal cohort to include broadly the same number of treated and control units in the sample, our baseline results are based on data from asymmetric windows around the pivotal cohorts for each reform. ${ }^{7}$ We show in section 6.4 that this choice does not affect our results. We further show the sensitivity of our estimates to the specification of our country-reform-specific trends in birth cohorts.

We estimate our model by 2SLS for the pooled sample of reforms. An econometric model for a single country (e.g. England) is equivalent to equations (1) and (2), with the

coefficient of compulsory schooling on years of education ranges between 0.22 and 0.40 , with the exception of Plug (2001) who finds 0.7 for males and 1.33 for females for the Netherlands. Overall, the estimates available in the literature on single-countries are comparable to those we find in this application.

${ }^{7}$ Due to data-limitations and the restriction that we use a cohort in a country only in our sample if we observe at least 10 women born in that cohort, our Sample 10/7 consists of only 4 post-reform cohorts in Denmark 1971, only 5 pre-reform cohorts in France 1936 and only 3 post-reform cohorts in the Netherlands 1971/75. 
exception that one is not able to control for cohort-fixed effects when only one country is considered. For the pooled sample of reforms, we are able to identify cohort effects because we observe birth cohorts in more than one country. ${ }^{8}$ In the regressions for Continental Europe, standard errors are clustered at the country-reform-cohort level. ${ }^{9}$ For England, we cluster at the level of the running variable, which is the birth cohort, as suggested by Lee and Card (2008) and done in McCrary and Royer (2011).

\section{Data}

We use data from the Survey of Health, Ageing and Retirement in Europe (SHARE), a longitudinal study that surveys representative samples of individuals aged 50 and above in several European countries. The English Longitudinal Study of Ageing (ELSA) has similar characteristics and covers England. In both surveys the respondents are interviewed every two years and asked about their health status, socio-economic conditions and their social lives. In this paper, we pool data of all women from the first four waves of SHARE (interviews in 2004/05, 2006/07, 2008/09 and 2011) and the second to the fifth wave of ELSA $\left(2004 / 05,2006 / 07,2008 / 09\right.$ and 2010/11). ${ }^{10}$

For both surveys, we use the latest available information for the individuals who participated in more than one interview. In ELSA around 15\% of all individuals in Sample 10 participated in only one interview. In SHARE around $57 \%$ participated in only one interview, with most of them being "new respondents" who joined the survey in 2011, as the SHARE sample was significantly extended in this year. A selected sample due to panel attrition is only a minor issue in our study, since we use all individuals who appeared at least once from wave 1 to 4 in SHARE and from wave 2 to 5 in ELSA.

\footnotetext{
${ }^{8}$ Note that due to the timing of the different education reforms and our sampling strategy, not all individual cohort effects can be identified in the pooled regressions either. We therefore combine the birth cohorts 1918-1926, 1933-1934 and 1961-1963.

${ }^{9}$ Clustering by country, with or without using the wild bootstrap procedure suggested by Cameron, Gelbach and Miller (2008) yield standard errors similar to those reported in the paper.

${ }^{10}$ Previous studies using a similar strategy cover a slightly larger number of countries by using data from the first wave of SHARE in combination with other sources (European Community Household Panel, International Social Survey Program, German Socio Economic Panel). However, those additional data sources would not allow us to measure cohort fertility in a consistent way across countries as SHARE and ELSA do.
} 
We use records of all females aged 45 or above to ensure that the women in our study already completed their fertility. ${ }^{11}$ We focus only on individuals who were born in the country of residence or migrated before the age of 5 to guarantee that they went to school in the host country at least at the early stages of their school career, i.e. when they were eligible for the changes induced by the reforms. ${ }^{12}$ Our final estimation samples, Sample $10 / 7$, include a total of $11,696 / 8,552$ observations.

We measure education as years of schooling. ELSA provides data on the age the individual left full-time education, with the following available answer categories in the questionnaire: not yet finished, never went to school, 14 or under, at 15, at 16, at 17, at 18, 19 or over. Based on this information, we calculated years of schooling by subtracting the school-entry age of 5 . Since the last category is open, we assumed 16 years of education for this category. SHARE provides information on the number of years spent in full-time education directly starting from the second wave. In the first wave of SHARE, the respondents were only asked about their educational degrees. Thus, we use the latest information available in the data and for those, who participated only in the first wave of SHARE (around 9\%), we calculated their years of schooling using country-specific conversion tables provided by the survey. ${ }^{13}$

Our dependent variables are measures of completed fertility. It is important to highlight that we consider cohort measures of fertility and not period measures. Period measures of fertility are generally based on cross-section data and measure current fertility, giving up-to-date information on levels. However, most of these measures are affected by distortions due to changes in the timing of events, the so-called tempo-effects. As a consequence, the period-measures are quite misleading estimates of the long-run fertility of a given population. The cohort measures of fertility are mainly based on longitudinal

\footnotetext{
${ }^{11}$ The survey includes individuals younger than 50 if they are younger spouses of core respondents who are aged 50 and above. Only $1.2 \%$ of the individuals in Sample 10 are younger than 50.

${ }^{12}$ We exclude records with missing information on key variables, such as years of education and number of children. We also exclude records of women whose age at first birth was below 15 or above 45 . Furthermore, we drop birth cohorts with fewer than 10 observations.

${ }^{13}$ Moreover, we corrected years of schooling by using the additional information on educational degrees (further and higher qualifications). We calculated the required years to achieve the stated qualification and used this measure for individuals with missing, zero or implausibly low values in the years of schooling question.
} 
or retrospective data. Their main advantage is that individuals belonging to the same cohort experience events (marriage, births) in the same socio-economic conditions (say, an economic boom, a recession period or a war), therefore those measures are not distorted by transient effects. Since we have micro-data of females with completed fertility, our measures refer to cohorts and not periods. As our measures of completed fertility, we use the number of biological children and a binary variable for childlessness. The number of biological children is censored at four, because prior to the fourth wave SHARE has given detailed information only for the first four children. However, only a minority of women (5.4\%) had more than 4 children in total (including non-biological ones). We control for this censoring by estimating a Tobit specification in section 6.3.

Table 2 reports descriptive statistics on key variables in Sample 10. The average number of biological children per woman in the sample is exactly at the replacement level. It is slightly below 2 in Denmark and Italy and is highest for the first reform in the Netherlands. However, due to differences in the timing of the reforms and the sampled cohorts, a comparison of variable means across countries is not meaningful. Since the number of biological children is censored at 4 , we report also the total number of children per woman, including step-children, adopted children, foster children and the children of the current spouses. This variable is slightly higher, 2.2 on average. The third column of the table shows the proportion of women without biological children, which is $12.3 \%$ on average. The mean age of women at their first birth is around 25, the average years of education is 10.9 and the average number of compulsory schooling years is 8.2. About $63 \%$ of the women in our sample are married at the time of the interview and about $94 \%$ are married or have been married in the past, i.e. including separated, divorced and widowed women. $11.6 \%$ declare to be separated or divorced at the time of the interview.

Our measures of the number of children only refer to those children who are still alive at the time of the interview. This could potentially affect our identification strategy if children of women whose education is affected by the reform are more likely to be still alive at the time of the interview. We postpone this discussion to section 6.1. 


\section{Results}

At first we have to show whether our data, which are combining reforms across different European countries, can in fact be pooled in a statistical sense. While we show the different estimation results separately for each reform in Appendix A.2 (see Table A1), we also performed a formal pooling test. ${ }^{14}$ We investigate whether country-specific coefficients are significantly different from each other in interacted regressions (IV, reduced form and first stage regressions). Starting with the number of biological children, it turns out that a pooled analysis of all countries is statistically not possible (the pooling hypothesis is rejected at the $1 \%$ level). The point estimates - while not all of them statistically significant, due to small sample sizes - are positive in Continental Europe, but negative in England. Once England is excluded, we cannot reject the hypothesis that the remaining countries can be pooled. This pattern is similar when we look at childlessness. From these results and the associated graphs (see Figures A-1, A-2 and A-3 in Appendix A.2), we conclude that it is sensible to separate England from Continental Europe, while Continental European countries can be pooled in a statistical sense.

We present our baseline results of the causal impact of schooling on the number of biological children and childlessness for England and Continental Europe in section 5.1. We discuss the external validity of our estimates, we characterize the subpopulation of compliers and we discuss the sign and magnitude of our baseline estimates with respect to the literature in section 5.2. Section 5.3 illustrates possible mechanisms and presents additional evidence on potential channels for the transmission of educational impacts on fertility, such as marriage behavior.

\subsection{Baseline results}

We first investigate the effects of the reforms on years of education (first stage) and the outcomes of interest (reduced forms). The first stage and the effect of the reforms on the number of biological children and childlessness for England and Continental Europe are shown graphically in Figures 1,2 and 3. Cohorts from different countries (or England)

\footnotetext{
${ }^{14}$ Full results are available upon request.
} 
are normalized with the compulsory schooling reforms, showing cohorts before and after the respective event. All graphs show adjusted mean values. ${ }^{15}$ The reforms had a sizable impact on years of education in both England and on the Continent: mean adjusted years of schooling are higher for cohorts affected by the new compulsory schooling legislation. Furthermore, the reduced form graphs show a drop in adjusted fertility at the time of the reform in England and a jump in fertility on the Continent. The Figures A-1, A-2 and A-3 in Appendix A.2 give equivalent graphs based on raw-data for each education reform separately.

Table 3 shows the estimated coefficients of education in regressions where we use the number of biological children and childlessness as outcome variables. We present results for Sample 10 and Sample 7 for England and Continental Europe. To facilitate the comparison between the specification for England and the pooled one, we also present the regressions for Continental Europe in which we do not control for cohort-fixed effects. The table contains OLS, 2SLS and reduced form estimates for both outcomes as well as first stage coefficients and F-Statistics.

Consistently across samples and specifications, the coefficients of the OLS regressions show the same signs as comparable correlation studies: years of education are negatively correlated with the number of biological children and positively correlated with childlessness. This holds for England and Continental Europe alike.

The first stage estimates indicate that the reforms actually had a sizable and statistically significant effect on schooling. One more year of compulsory education increased schooling by about 0.7 years in England and around 0.3 years on the Continent. The magnitude for Continental Europe is similar to other studies that pool compulsory schooling reforms in Europe (Brunello et al., 2013, 2009; Schneeweis et al., 2014). Devereux and Hart (2010) report a first stage effect of 0.55 for the 1947 reform in England. The F-Statistics of

\footnotetext{
${ }^{15}$ We calculate the residuals from a regression of years of education or the respective fertility measure on a vector of control variables (such as indicators for interview years, foreign born and proxy interviews) and linear trends in birth cohorts that differ before and after for England as well as country-reform-fixed effects and country-reform interactions of the trends for Continental Europe and additional cohort-fixed effects for Continental Europe with cohort fixed effects. The graphs show mean values of these residuals by birth cohort (relative to the pivotal cohort). The circle areas are proportional to the number of observations available in each cell.
} 
the excluded instrument in the first stage ranges from about 19 to 29, indicating that the instrument is sufficiently correlated with the endogenous variable (Staiger and Stock, 1997).

The reduced form estimates confirm the graphical inspection and the opposing results for England and the Continent. In England, mandatory education reduced the number of biological children, while on the Continent it raised fertility. The reduced form estimates for childlessness are negative and statistically significant for the Continent.

The two-stage least-squares estimates have the same signs as the reduced forms. When we instrument years of education with the number of compulsory schooling years in England, we obtain negative significant coefficients for the number of children at around 0.3. Childlessness is statistically significant with the smaller sample only at the 10-percentlevel. When considering Continental Europe, all coefficients from the OLS estimations change their signs and are statistically significant, i.e. additional schooling increased fertility on the Continent. One additional year of schooling have raised the number of biological children by $0.2-0.3$ and have decreased childlessness by about $5-11$ percentage points.

\subsection{Interpretation}

We observe a negative causal effect of education on fertility in England and a positive relationship in Continental Europe. Interestingly, all OLS coefficients are statistically significant and negative for the number of biological children and positive for childlessness, also in Continental Europe. If the causal effect of education on fertility is positive on the Continent, why are those variables negatively correlated in OLS regressions? One explanation is, that the OLS results are biased downwards because of omitted variables. Assume the true econometric model to be

$$
\text { Fertility }_{\text {irk }}=\gamma_{0}+\gamma_{1} \text { Edu }_{i r k}+\gamma_{2} \text { Family }_{\text {irk }}+\ldots+\nu_{i r k}
$$


with Family capturing positive attitudes towards the family or preferences for having children. Assume that $\gamma_{1}>0$ and $\gamma_{2}>0$, i.e. education and family-orientation are positively related to fertility. Furthermore, family-orientation is negatively related to years of education because women often have to decide between being family or careeroriented, i.e. $\operatorname{Cov}(E d u$, Family $)<0$. If family-orientation is omitted from the regression and sufficiently correlated with education, the OLS coefficient on education will be biased downwards. ${ }^{16}$

We interpret our results as Local Average Treatment Effects, i.e. the effect of education on fertility for those who changed their schooling attainment because they have been affected by the reforms (compliers). Since we are analyzing compulsory schooling reforms, our estimates should apply to those at the bottom of the education distribution. Figure 4 shows the distribution of years of education for the cohorts before and after the respective reforms. The graph shows that the reforms had the largest effects for those with few years of education. The vertical distance between the two cumulative density functions is largest between 6 and 10 years of education. ${ }^{17}$

Though it is not possible to identify compliers using observable data because they are defined by means of counterfactual outcomes, we can characterize the population of compliers with respect to some interesting pre-treatment variables, as suggested by Angrist (2004). The compliers' population can be easily described by exploiting Bayes Theorem when both, the treatment (education) and the instrument (compulsory schooling) are binary variables. The extension of the procedure to continuous or discrete variables is not trivial, thus, we re-coded our treatment and instrument as binary. ${ }^{18}$ For a sub-sample of respondents, both surveys provide retrospective information about the respondent's

\footnotetext{
${ }^{16}$ Normalize family-orientation between 0 (no family-orientation) and 1 (highest family-orientation). If $\gamma_{2}=1$, then women with the highest level of family-orientation have one child more than those with the lowest level of family-orientation. In that case, a slope coefficient of -0.246 from the regression of family-orientation on years of schooling (in sample 10) would explain the difference between the OLS and the IV model.

${ }^{17}$ Brunello et al. (2009) show that the estimated education effects that stem from compulsory schooling reforms are largest at the bottom of the education distribution using quantile regression techniques.

${ }^{18}$ The treatment is a binary indicator taking the value 1 if the individual's actual years of education are equal or exceed the post-reform number of mandatory schooling years and 0 otherwise. The instrument is a binary indicator taking the value 1 for post-reform cohorts. For this exercise, we consider only reforms for which the new mandatory schooling prescribed a one-year increase, so that the coefficient for the instrument has the same interpretation in all countries.
} 
histories (gathered in the interviews in 2008/09 in SHARE and 2007 in ELSA). Using these interviews, we select pre-treatment variables that are similarly reported in the two surveys and can be considered as proxies for family attitudes and/or parental background, namely: (i) a binary indicator of whether the individual had few books at home when aged 10 (between 0 and 10 books) and (ii) a binary indicator taking the value 1 if the individual used to live in a large household when aged 10, i.e. an household with more persons compared to the country median in the sample. Furthermore, from the normal interviews we construct (iii) a binary indicator taking the value 1 if the individual has more (alive) siblings with respect to the country median (2 in most countries).

For Continental Europe, we find that compliers tend to be: $81 \%$ more likely to have had few books at home when aged 10, 57\% more likely to come from large households and $47 \%$ more likely to have many siblings (compared to the sample averages). For England, we find the same pattern but smaller magnitudes $(25 \%, 23 \%$ and $32 \%)$. We interpret these results as suggestive evidence that compliers in our study have a poorer family background and come from larger families, thus might be more family-oriented than the average individual in the sample. Our estimates apply to this sub-sample of the female population only: for these women the effect of education on fertility might differ from the average woman in the population.

Overall, our findings show positive causal effects of education on fertility in Continental Europe and a negative effect in England using the 1947 reform. As described in Section 2, Monstad et al. (2008), Fort (2009) and Geruso and Royer (2014) found no significant effects of education induced by mandatory schooling in Norway, Italy and the 1972 reform in the UK on total fertility. ${ }^{19}$

Leon (2004) found a negative impact of education on fertility of around -0.33 and a small positive effect on childlessness for the US. Similarly, Cygan-Rehm and Maeder (2013) examined Germany and found a negative effect on the number of children of about -0.15 and a positive effect on childlessness of 0.06. On the other hand, Braakmann (2011),

\footnotetext{
${ }^{19}$ While the coefficients the authors obtained are statistically not significant, the point estimate for the number of children is negative in Norway, rather positive than negative in Italy and positive and negative depending on the specification in the UK.
} 
investigating also the 1972 UK reform as Geruso and Royer (2014) did, found a positive impact of education on the number of children. One major drawback of this study is that the author is able to see only the number of children below the age of 19 in the data.

In the light of this literature and given our results for the European Continent and England, it seems that fertility effects of education differ across countries or time periods. Education might influence fertility through different channels, such as the labor market or the marriage market. These channels, in turn, might be affected by education in a different way depending on cultural and institutional characteristics of the countries.

\subsection{Mechanisms}

Two important channels for potential effects of education on fertility are the labor market, on the one hand, and the marriage market, on the other hand. Higher wages - triggered by higher education - would predict a decrease or increase in fertility, depending on the dominance of substitution and income effects, provided children are normal goods. There might be differences between England and Continental Europe with respect to females' labor force attachment. In our sample, on the Continent, approximately $92 \%$ of women said that they had been active on the labour market for at least six months; this figure is close to 100\% for England. Accounting for cohort-differences in our sample, all countries in Continental Europe have a significantly lower proportion of women on the labor market than England. If females are less attached to the labor market on the Continent and more family-oriented, income effects might dominate substitution effects there.

Using instrumental variable quantile regressions and some of the reforms used in this study, Brunello et al. (2009) find that education induced by mandatory schooling reforms increased earnings for both males and females, with the largest effect for females and at the bottom of the conditional wage distribution for both genders. The causal effect of one additional year of schooling is $4 \%-7 \%$ for males and $5 \%-10 \%$ for females. The authors also summarize the evidence on wage returns to education from single-country studies that exploit compulsory schooling reforms for identification and conclude that most studies report positive returns. 
However, not all studies find wage effects to compulsory schooling reforms. Devereux and Hart (2010) do not find any monetary returns to the 1947 compulsory schooling law change for women in England and Pischke and von Wachter (2008) find zero returns of the compulsory schooling reforms during the 1940s-1960s in Germany. Furthermore, comparing the 1972 reform in England and Wales to the 1959 reform in France, Grenet (2013) finds no evidence of returns in France but significant gains in England. The author concludes that the difference stems from the impact the reform had on academic qualifications in England but not in France.

Overall, the results for England in our study have to be interpreted with having in mind that the reform in 1947 had no effects on female wages. Thus, the labor market effect via increased wages may not be present in England at all. ${ }^{20}$ As Bingley et al. (2005) show, female labour force participation in England may have increased due to increased schooling even in the absence of any wage effects (e.g. due to changes in attitudes towards work).

A second potential mediating channel is marriage behavior. We investigate whether education is related to the probability and stability of marriage. Panel A of Table 4 presents OLS and 2SLS estimates of education on marriage behavior, i.e. on a binary variable for being ever married, currently married and separated or divorced. The OLS model shows that education is negatively correlated with an indicator variable of ever being married in England and on the Continent. Furthermore, it is also negatively correlated with currently being married on the Continent and positively correlated with this variable in England. The OLS estimate for being separated/divorced is positive and significant only for the Continent.

When taking care of the endogeneity of education, almost all coefficients for Continental Europe change their signs. According to the 2SLS estimations, one additional year of education increases the likelihood that a women got married at some point in her life by around 5\%-points and that she is married at the time of the interview by around $7 \%$ -

\footnotetext{
${ }^{20}$ Note that the zero wage effects obtained by Pischke and von Wachter (2008) for the reforms in Germany have to be taken into account when interpreting the negative effects of education on fertility for Germany obtained by Cygan-Rehm and Maeder (2013).
} 
points. The results for England are different and point towards a negative relationship of education and the probability of being married. The stability of marriage, as measured by separation/divorce does not seem to be affected by additional schooling. Overall, these results are in line with our estimates for fertility: more education improves the chance of getting married in Continental Europe and decreases marriage rates in England, ${ }^{21}$ which, in turn, might partly be responsible for the contrasting effects of education on fertility.

Next to its effect on the likelihood of marriage, education might improve the quality of the husband, which we proxy by education. Panel B in Table 4 presents an analysis of this channel, based on a restricted sample of married women. ${ }^{22}$ The OLS coefficients are all positive and statistically significant. When taking care of the endogeneity of female education, we obtain a positive and significant coefficient of around 0.56 in England. On the Continent, the coefficients are between 0.37 and 0.72 and are statistically significant only in one out of four versions of the model. Overall, the coefficients in Panel B are relatively large and indicate a high degree of assortative mating, at least in England.

Higher education of the partner will increase the partners' wage rate on the labor market and, again, the magnitudes of substitution and income effects will determine the consequences for the number of children the family chooses to have. The existence of a substitution effect for husbands will depend on the division of tasks and responsibilities between the couple in the household. For most countries and time periods in our study, the income effect of the husband might probably dominate the substitution effect and, if children are normal goods, will increase fertility of the family. Note, that these effects are conditional on having a partner, which is negatively affected by education in England and positively affected in Continental Europe.

Overall, the investigation of mediating effects through the labor and marriage market point towards important differences between England and our set of Continental European countries. Our opposing effects of education on fertility in England and on the Continent are to be viewed in the light of these differences.

\footnotetext{
${ }^{21}$ See also Anderberg and Zhu (2014) for similar evidence on marital outcomes in the UK.

${ }^{22}$ Note that we observe the years of education for the spouses of currently married women. Additionally, in SHARE we observe the educational degrees (higher and further degrees) of former spouses of women who are not currently married but have been married in the past.
} 


\section{$6 \quad$ Sensitivity analysis}

This section presents several sensitivity checks and falsification tests. We will show that our estimates are not confounded with any selection biases. In section 6.1, we deal with the potential confounder of selective mortality of the respondents themselves and their children. In section 6.2, we subject our econometric model to placebo tests while in section 6.3 we explore the robustness of the results with respect to the choice of the regression model. Finally, we investigate the robustness of our estimates with respect to the sampling window and the trend-specification in section 6.4 .

\subsection{Fertility and mortality}

One potential confounder may be selective mortality of the respondents themselves and their children. The older cohorts in our sample may be positively selected with respect to their health, since these individuals are still alive and able to participate in the SHARE and ELSA interviews. ${ }^{23}$ One concern is that these individuals might be selected with respect to fertility as well. If mortality is related to fertility in the way that childless women and women with fewer biological children live longer, our estimates might reflect these patterns. This would mean that in our control group (older cohorts with fewer years of compulsory education), the less fertile women might be over-represented, which might then be an explanation for the positive coefficient in the education-fertility relation in Continental Europe.

One big advantage of our cross-country estimation strategy for Continental Europe is that we are able to control for cohort fixed effects additionally to the country-reformspecific time trends. For England, only the trends in birth cohorts that differ before and after the reform control for unobservable differences between birth cohorts. Our sampling strategy with choosing only up to $10 / 7$ cohorts before and after each reform should also contribute to minimize any unobserved differences between pre- and postreform individuals. Thus, a large part of a potential mortality-related selectivity should

\footnotetext{
${ }^{23}$ Gathmann, Juerges and Reinhold (2014) studied the effects of schooling on mortality investigating 19 compulsory schooling reforms in Europe. While schooling benefits male life-expectancy, there is little or no effect for females.
} 
already be eliminated. This relates also to worries that some cohorts might be intrinsically different due to the effects of World War II.

To eliminate any further biases, we pursue three different strategies: (i) we review the literature on the relationship between fertility and mortality, (ii) we estimate our models by controlling for differences in the life-expectancy of individuals born in different years and countries and (iii) we restrict our analysis for Continental Europe to younger cohorts for whom any mortality-selection should be less severe.

The literature on the relation between the number of children a wife has born and mortality is unclear; there are some papers showing correlations but no causal analyses. Studies for previous centuries find a positive correlation between parity and mortality (Doblhammer and Oeppen (2003) looking at English peers starting from 1500 onwards as well as Smith et al. (2002) using Utah couples from 1860-1899). This might be due to medical risks directly related to childbirth. Studies using more recent data are inconclusive: Hank (2010) finds no effect for Germany and Hurt, Ronsmans and Thomas (2006) find no relation between parity and mortality in a meta-study; if ever mortality risk is highest for women without children and those with more than four children. ${ }^{24}$

In Table 5 we present several regressions that take care of a potential selective mortality bias. The first rows in Panel A and B show 2SLS-estimations in which we control for the life-expectancy of the individual. For this purpose, we collected data on lifeexpectancy at birth from the Human Mortality \& Human Life-Table Databases. ${ }^{25}$ Adding life-expectancy to the regressions does not significantly change our estimates. In the second rows of Panel A and B, we weight the individuals according to their life-expectancy. While younger cohorts in our sample are generally aged below their life-expectancy, the older cohorts are above. As weights we use weight $=1 /($ age - life-exp $)$ if age $>$ life-exp, 1 otherwise, i.e. individuals who are older than their life-expectancy get less weight in the regressions. The 2SLS coefficients are, again, very similar to the baseline results.

\footnotetext{
${ }^{24}$ See also Doblhammer (2000) and Grundy and Tomassini (2005).

${ }^{25}$ Max Planck Institute for Demographic Research (www.demogr.mpg.de), data for the cohorts 19201956. In Austria, data are missing for some cohorts, so we linearly interpolated the missing values (cohorts 1941-1946). For the birth cohorts 1918 and 1919 in France, we use the 1920 value and for the cohorts born after 1956, we use the life-expectancy of the 1956 cohorts. Our measures are period-measures of life-expectancy at birth since cohort measures of life-expectancy at birth are not available.
} 
Finally, the third rows in Panels A and B show estimates for a restricted sample of younger cohorts born 1940 and afterwards. ${ }^{26}$ We are not able to provide this sensitivity check for England and we have to drop the early reforms in France and the Netherlands from our sample. For this test, we argue that the recent cohorts are younger at the time of the interview and selectivity on the basis of mortality differences will be less severe. If our baseline results of a positive effect of education on fertility were driven by a selectivity bias, the estimates for recent cohorts should be significantly smaller than the baseline results. The estimated coefficients show that this is not the case. Overall, the evidence given in Table 5 suggests that our results are not driven by selective mortality of the respondents.

As described above, we only observe the children of the respondents if they are still alive at the time of the interview. The older cohorts in our sample might have had more children who are not alive anymore and therefore not counted in the dependent variable. Thus, we may have a measurement error problem, with the measurement error being potentially correlated with explanatory variables, the cohorts and most importantly our instrument, years of compulsory schooling. This problem is very similar to the selective mortality of the respondents themselves and the same sensitivity analysis applies. If our results would stem from selective mortality of the children of the respondents, the magnitude of the coefficients would get smaller if only recent cohorts are used for the analysis (for whom the measurement error should be smaller) or if life-expectancy is accounted for. As Table 5 shows, this is not the case. Furthermore, the average age at first birth of the women in our sample is nearly 25 and their age at the time of the interview is 65 on average. Thus, their oldest child should only be 40 years old at the time of the interview.

However, this sensitivity analysis does not apply if education reduces child mortality compared to general mortality at older ages. Education might not influence the number of births a women has, but might increase the probability that the child is still alive at the time of the interview. More educated women might behave more healthy during

\footnotetext{
${ }^{26}$ This restriction also takes care of the argument, that our sample persons might be hampered by wartime effects: for these women, schooling started after World War II. Furthermore, the results are broadly consistent when only women born after 1945 are included in the estimations.
} 
pregnancy or invest more in their children's health due to better knowledge or income effects. For the U.S., there are two studies focusing on the effect of maternal education on infant health. While McCrary and Royer (2011) use age at school entry as instrument for maternal education and find no significant effects, Currie and Moretti (2003) use college openings and find significant effects on birth weight, the incidence of a premature birth and prenatal care. Comparing the results of these two studies suggests that education has a positive effect on the health of the child only at higher levels of education.

If education, in fact, reduces infant mortality, the results obtained above for Continental Europe may stem from these effects rather than from labor or marriage market effects as discussed above. There is one feature of the SHARE and ELSA data that helps us to reject this hypothesis. At the time of the third wave (2008/09 in SHARE and 2007 in ELSA), retrospective life-interviews have been conducted and the respondents were asked: "Have you had another (ever had) a biological child - even one who only lived for a short time?" Using this information, we construct an indicator variable of whether a person never had a biological child.

Table 6 presents the results of this sensitivity check. The first line in the table replicates the baseline results for childlessness at the time of the interview with the smaller sample of individuals who took part in the retrospective life-interviews. In England, around $60 \%$ and in Continental Europe only $35 \%$ took these interviews. ${ }^{27}$ In England, the point estimates are similar to the baseline results for Sample 10 and somewhat larger with Sample 7. When replacing the dependent variable with the variable constructed from the life-interviews, the effects are very similar: the effect of education on childlessness at the time of interview does not differ from the effect of education on the probability of never having any biological child. Considering Continental Europe, the two different definitions of childlessness give very similar point estimates. However, while the coefficients are

\footnotetext{
${ }^{27}$ Although the whole third wave interviews have been replaced by the life-interviews in SHARE, the fraction is still low because the survey has been expanded considerably at the time of the fourth wave, i.e. after the life interviews had been conducted. Around $43 \%$ of our sample members have been "new respondents" in wave 4. In ELSA, the life-interview did not replace the usual questionnaire but has been conducted additionally. However, only core-respondents who were initially sampled for the survey (not the other household members) and who had finished their third wave questionnaire before April 19, 2007 have been asked to take part in the additional life-interview. The fraction in ELSA is, however, still larger than in SHARE because the survey has not been expanded after the third wave.
} 
negative, both differ from the baseline results in terms of magnitude. The first stage for the smaller samples are given at the bottom of the table. While the first stage is fine for England, it is very weak for Continental Europe, which may explain the lower precision in the IV estimates. Overall, given the evidence for England and the similarity of the point estimates for the two definitions of childlessness, we interpret the results as evidence that potential child mortality is not biasing our baseline results.

\subsection{Placebo treatments}

As compulsory schooling reforms are only effective as they influence cohorts differently, one might be concerned that our school reform variables pick up some unspecified time trend or structural changes in the respective countries instead of a true treatment effect. To test for this, we are using two types of placebo tests.

First, similar to Black et al. (2008) we introduce a hypothetical compulsory schooling reform for each of our countries. Thus, for each individual, in the reduced form estimations we add a variable capturing hypothetical compulsory schooling, changing its value three years prior to the actual reform. This placebo reform should not have any impact on fertility. If we find an impact of a non-existing reform, we should get suspicious: our supposedly reform-based results might as well be driven by other unobserved mechanisms, such as selective mortality or structural breaks. ${ }^{28}$

Second, we estimate reduced form regressions and replace the actual compulsory schooling level a person has been exposed to with a randomly allocated compulsory schooling level. This randomization is done for each country and reform. Again, the placebo compulsory schooling level should not have any impact on fertility. If we find an impact, the validity of our Instrumental Variables strategy is questionable. As both placebo reforms, by definition, will have no impact on attended years of schooling, we can only use the reduced form estimates to test for a potential placebo effect.

Table 7 shows the reduced form estimates for the number of biological children and childlessness for the baseline model as well as for both placebo experiments. The baseline

\footnotetext{
${ }^{28}$ Note that we have to include the actual compulsory schooling level in these regressions as well, as placebo and real reform overlap systematically for some cohorts.
} 
results are given in columns (1), (4) and (7). Adding placebo schooling reforms three years in the past (see columns (2), (5) and (8)), does not alter our estimated reduced form estimates for the real reforms and the coefficients of the placebo reforms are numerically much smaller and statistically not significant, i.e. none of the prior placebo laws has any impact on fertility. Furthermore, the results of the randomization exercise are also reassuring: none of the placebo levels of compulsory schooling has any impact on fertility (see columns (3), (6) and (9)).

\subsection{Functional form}

So far, we presented results of linear regression models. However, our data present two characteristics that may be relevant for the choice of the regression model: first, the number of children in a family takes only non-negative integer values, so that count data regression models, such as Poisson regressions would be more appropriate choices and second, our data on the number of biological children are (right) censored at four, thus we should consider regression models that allow for censoring.

When we estimate Poisson regression models accounting for the endogeneity of education, the average partial effect on the number of children ranges from 0.15 to 0.23 for the Continent, depending on whether we include cohort fixed effects or not and is about -0.16 in England. These estimates are statistically significant and are somewhat smaller in magnitude than our 2SLS estimates.

Since the distribution of the number of biological children is approximately normal but right censored, we also estimate Tobit regression models by maximum likelihood. ${ }^{29}$ The results are given in Table 8. Here, we model the decision on entering motherhood and the decision on the actual number of children jointly, allowing for a correlation between these choices. ${ }^{30}$ We allow for right censoring at 4 and a corner solution at 0 . Using these estimates, we assess the average partial effects of education on the probability of being

\footnotetext{
${ }^{29}$ Around $13 \%$ of the women in our Sample 10 have no biological children, $20 \%$ have one child, $39 \%$ have two, $18 \%$ have three and around $10 \%$ have four or more biological children.

${ }^{30}$ This comes at the expense of imposing the same coefficient on education in the equation determining the two choices, as in standard Tobit models. Otherwise we would need an instrument for education in the motherhood equation that can be excluded from the equation for the number of children, once the woman entered motherhood.
} 
childless and on the average number of children for women who decide to (i) have at least one child and (ii) have more than one but not more than four children. Tobit as well as IV-Tobit estimations are presented for England and Continental Europe, again with and without cohort-fixed effects. These regressions confirm previous results in terms of the direction of the effects: the association between education and fertility is negative in all estimations and the causal effect is negative in England and positive in Continental Europe, with larger coefficients obtained when cohort-fixed effects are included. Compared to the linear 2SLS estimations presented above, the magnitudes of the average partial effects are somewhat smaller in the IV-Tobit models. We find that one year of additional education induced by compulsory schooling extensions raised childlessness in England by 4 percentage points and reduced this phenomenon in Continental European countries by $4-5$ percentage points. Given an average of $12.3 \%$, these effects are still quite large. Moreover, conditional on having children, education shifted the number of children by -0.24 in England and by +0.18 to +0.25 on the Continent. The effect for women who have $2-4$ children is -0.08 in England and around +0.06 in Continental Europe. ${ }^{31}$

\subsection{Further robustness}

Finally, we show that our results are robust to the choice of symmetric sampling windows around the pivotal birth cohorts and the introduction of quadratic trends in birth cohorts in the estimations. Table 9 shows 2SLS-estimations as well as first stage coefficients and F-Statistics for both robustness checks. When sampling the same number of birth cohorts before and after each reforms (with 10 cohorts at most), all point estimates are similar to the baseline results. Replacing the linear trends (that differ before and after each reform) with one more flexible quadratic trend in cohorts also give practically the same point estimates as in the baseline estimations.

\footnotetext{
${ }^{31}$ Measurement error in the dependent variables is unlikely to drive our findings: we validate our data comparing descriptive statistics at the country-cohort level with those available in the literature (Council of Europe, 2002; D'Addio and D'Ercole, 2005; Gustafsson, 2001; Thevenon, 2010) for selected countries and cohorts and find that measures of cohort fertility in our sample are broadly consistent with the literature, albeit we tend to underestimate childlessness with compared to Gustafsson (2001). More details on this issue are available from the authors upon request.
} 


\section{Concluding remarks}

We study the effects of education on fertility for women in several European countries using exogenous variation in education brought along by mandatory schooling reforms in the 1930s-70s. Separate estimates by education reform and formal poolability tests indicate that we are able to pool all countries and reforms across Continental Europe. For England, we find significantly different coefficients, so we show the results for England and the Continent separately throughout the paper.

Surprisingly and contrary to conventional wisdom, we find that the additional schooling generated by the compulsory schooling extensions led to an increase in fertility in Continental Europe. We find that one additional year of schooling increased the number of biological children by $0.2-0.3$ and decreased the probability to remain childless by $4-11$ percentage points, depending on the specification and estimation strategy. For England, the results point in the opposite direction. A number of falsification and robustness tests, like placebo experiments, tests for functional form or selective mortality in the sample corroborate our findings for both, England and the Continent.

We interpret our results as Local Average Treatment Effects, i.e. the effect of schooling for those women who changed their schooling decisions due to the mandatory schooling reforms. These should mainly be women at the lower end of the education distribution. The compliers to these reforms in our sample can be described with respect to pre-treatment variables. We show that our identification strategy targets a specific group in the population: our compliers have grown up in poorer and larger households and have more siblings relative to the average woman in the sample. While this is true on the Continent and in England, these characteristics are more pronounced in Continental Europe.

We also tried to shed some light on the potential mechanisms behind our results. The answer to the question why we find such opposing effects for England and Continental Europe may be found in different effects of schooling on mediating channels. We investigate two important markets, the labor market and the marriage market. Given the high returns to education caused by lengthening compulsory schooling in Continental Europe (Brunello et al., 2009), the income effect of increased schooling may have outweighed 
the substitution effect, thus increasing fertility. In England, on the contrary, mandatory schooling reforms did not lead to wage increases for women (Devereux and Hart, 2010). Likewise, on the Continent, more education led to fewer women who remained unmarried over their life-course, which also might trigger fertility. Among women in England, the effects of education induced by compulsory schooling reduced marriage rates. These differential impacts of education in both these markets may combine to explain the contrasting phenomena.

Research on non-monetary effects of education has expanded enormously in recent years (Oreopoulos and Salvanes, 2011). Assessing the impact on fertility, in particular at the lower end of the educational distribution, is an important part of it. Our research shows that previously assumed socio-economic gradients may be invalid: for low-educated females in Continental Europe, more education did not reduce fertility, on the contrary. Extending compulsory education, as is discussed in some countries, may thus not lead to a shrinking population. 


\section{References}

Adsera, Alicia (2005), 'Vanishing children: From high unemployment to low fertility in developed countries', American Economic Review Papers and Proceedings 95, 189-193.

Ahn, Namkee and Pedro Mira (2002), 'A note on the changing relationship between fertility and female employment rates in developed countries', Journal of Population Economics 15, 667682.

Albouya, Valerie and Laurent Lequien (2009), 'Does compulsory education lower mortality?', Journal of Health Economics 28, 155-168.

Amin, Vikesh and Jere R. Behrman (2014), 'Do more-schooled women have fewer children and delay childbearing? Evidence from a sample of U.S. twins', Journal of Population Economics 27, 1-31.

Anderberg, Dan and Yu Zhu (2014), 'What a difference a term makes: the effect of educational attainment on marital outcomes in the UK', Journal of Population Economics 27, 387-419.

Angrist, Joshua D. (2004), 'Treatment effect heterogeneity in theory and practice', The Economic Journal 114, C52-C83. Issue 494.

Angrist, Joshua D. and Alan Krueger (1991), 'Does compulsory school attendance affect schooling and earnings?', Quarterly Journal of Economics 106, 979-1014.

Arendt, Jacob Nielsen (2005), 'Does education cause better health? A panel data analysis using school reforms for identification', Economics of Education Review 24(2), 149-160.

Arendt, Jacob Nielsen (2008), 'In sickness and in health - till education do us part: Education effects on hospitalization', Economics of Education Review 27(2), 161-172.

Battistin, Erich, Agar Brugiavini, Enrico Rettore and Guglielmo Weber (2009), 'The retirement consumption puzzle: Evidence from a regression discontinuity approach', American Economic Review 99(5), $2209-2226$.

Becker, Gary S. (1965), 'A theory of the allocation of time', Economic Journal 75, 493-517.

Becker, Gary S. and H. Gregg Lewis (1973), 'On the interaction between quantity and quality of children', Journal of Political Economy 81, S279-S288. 
Behrman, Jere R. and Mark R. Rosenzweig (2002), 'Does increasing women's schooling raise the schooling of the next generation?', American Economic Review 92(1), 323-334.

Bingley, Paul, Yu Zhu and Ian Walker (2005), 'Education, work and wages in the UK', German Economic Review 6(3), 395-414.

Black, Sandra E., Paul J. Devereux and Kjell G. Salvanes (2008), 'Staying in the classroom and out of the maternity ward? The effect of compulsory schooling laws on teenage births', Economic Journal 118(July), 1025-1054.

Braakmann, Nils (2011), Female education and fertility - Evidence from changes in British compulsory schooling laws, Discussion Paper 2011/05, Newcastle Discussion Papers in Economics.

Brunello, Giorgio, Daniele Fabbri and Margherita Fort (2013), 'The causal effect of education on the body mass: Evidence from Europe', Journal of Labor Economics 31(1), 195-223.

Brunello, Giorgio, Margherita Fort and Guglielmo Weber (2009), 'Changes in compulsory schooling, education and the distribution of wages in Europe', Economic Journal 119(March), 516539.

Cameron, A. Colin, Jonah B. Gelbach and Douglas L. Miller (2008), 'Bootstrap-based improvements for inference wth clustered-errors', The Review of Economics and Statistics 90(3), 414427.

Council of Europe (2002), Recent demographic developments in Europe, Technical report.

Currie, Janet and Enrico Moretti (2003), 'Mother's education and the intergenerational transmission of human capital: Evidence from college openings', Quarterly Journal of Economics 118(4), 1495-1532.

Cygan-Rehm, Kamila and Miriam Maeder (2013), 'The effect of education on fertility: Evidence from a compulsory schooling reform', Labour Economics 25, 35-48.

D'Addio, Anna C. and Marco M. D'Ercole (2005), Trends and determinants of fertility rates in OECD countries: The role of policies, Social, Employment and Migration Working Papers 27, OECD. 
Dehejia, Rajeev and Adriana Lleras-Muney (2004), 'Booms, busts, and babies' health', Quarterly Jorunal of Economics 119, 1091-1130.

Del Bono, Emilia, Andrea Weber and Rudolf Winter-Ebmer (forthcoming), 'Fertility and economic instability: The role of unemployment and job displacement', Journal of Population Economics .

Devereux, Paul J. and Robert A. Hart (2010), 'Forced to be rich? Returns to compulsory schooling in Britain', Economic Journal (549), 1345-1364.

Doblhammer, Gabriele (2000), 'Reproductive history and mortality later in life: A comparative study of England and Wales and Austria', Population Studies 54, 169-176.

Doblhammer, Gabriele and Jim Oeppen (2003), 'Reproduction and longevity among the British peerage: The effect of frailty and health selection', Proceedings of the Royal Society of London. Series B: Biological Sciences 270(1524), 1541-1547.

Duflo, Esther, Pascaline Dupas and Michael Kremer (2010), Education and fertility: Experimental evidence from Kenya. MIT Working Paper.

Fonseca, Raquel and Yuhui Zheng (2011), The effect of education on health: Cross-country evidence. RAND Working Paper WR-864.

Fort, Margherita (2006), 'Education reforms across Europe: A toolbox for empirical research'. Paper version: May 11, 2006, mimeo.

Fort, Margherita (2009), Evidence on the causal impact of education on fertility, Technical report, University of Bologna. Paper version: February 14, 2009, mimeo. Previously circulated as ISER-WP 2005 n. 20, EUI MWP WP 2007 n. 22.

Garrouste, Christelle (2010), 100 years of educational reforms in Europe: A contextual database, European Commission Joint Research Center, Luxembourg: Publications Office of the European Union.

Gathmann, Christina, Hendrik Juerges and Steffen Reinhold (2014), 'Compulsory schooling reforms, eudcation and mortality in 20th Century Europe', Social Science and Medicine. forthcoming. 
Geruso, Michael and Heather Royer (2014), The impact of education on family formation: Quasiexperimental evidence from the UK. mimeo (Version: July 21, 20114).

Grenet, Julien (2013), 'Is extending compulsory schooling alone enough to raise earnings? Evidence from French and British compulsory schooling laws', Scandinavian Journal of Economics 115(1), 176-210.

Grundy, Emily and Cecilia Tomassini (2005), 'Fertility history and health in later life: A record linkage study in England and Wales', Social Science E Medicine 61(1), 217-228.

Gustafsson, Siv (2001), 'Optimal age at motherhood: Theoretical and empirical considerations on postponement of maternity in Europe', Journal of Population Economics 14, 225-247.

Hank, Karsten (2010), 'Childbearing history, later-life health, and mortality in Germany', Population Studies 64(3), 275-291.

Harmon, Colm and Ian Walker (1995), 'Estimates of teh economic return to schooling for the United Kingdom', American Economics Review 85(5), 1278-1286.

Hurt, Lisa S., Carine Ronsmans and Suzanne L. Thomas (2006), 'The effect of number of births on women's mortality: Systematic review of the evidence for women who have completed their childbearing', Population Studies 60(1), 55-71.

Kirdar, Murat G., Meltem Dayioglu Tayfur and Ismet Koc (2011), The effect of compulsory schooling laws on teenage marriage and births in Turkey. IZA Discussion Paper 5887.

Lee, D. S. and D. Card (2008), 'Regression Discontinuity Inference with Specification Error', Journal of Econometrics 142(2). Special issue: The Regression-Discontinuity Design - Theory and Applications.

Lefgren, Lars and Frank L. McIntyre (2006), 'The relationship between women's education and marriage outcomes', Journal of Labor Economics 24(4), 787-830.

Leon, Alexis (2004), The effect of education on fertility: Evidence from compulsory schooling laws, Technical report, University of Pittsburgh. Paper version: November 24, 2004, mimeo.

Levin, Jesse and Erik J. S. Plug (1999), 'Instrumenting education and the returns to schooling in the Netherlands', Labour Economics 6, 521-534. 
Martin, Teresa Castro (1995), 'Women's education and fertility: Results from 26 demographic and health surveys', Studies in Family Planning 26(4), 187-202.

McCrary, Justin and Heather Royer (2011), 'The effect of female education on fertility and infant health: Evidence from school entry policies using exact date of birth', American Economic Review 101/1, 158-195.

Monstad, Karin, Carol Propper and Kjell G. Salvanes (2008), 'Education and fertility: Evidence from a natural experiment', Scandinavian Journal of Economics 110(4), 827-852.

Murtin, Fabrice and Martina Viarengo (2011), 'The expansion and convergence of compulsory schooling in Western Europe, 1950-2000', Economica 78, 501-522.

Oreopoulos, Philip and Kjell G. Salvanes (2011), 'Priceless. The nonpecuniary benefits of schooling', Journal of Economic Perspectives 25(1), 159-184.

Pischke, Joern-Steffen and Till von Wachter (2008), 'Zero returns to compulsory schooling in Germany: Evidence and interpretation', Review of Economics and Statistics 90(3), 592-598.

Plug, Erik J. S. (2001), 'Season of birth, schooling and earnings', Journal of Economic Psychology 22, 641-660.

Rose, Elaina (2003), Does education really disadvantage women in the marriage market? mimeo, University of Washington, Seattle.

Schneeweis, Nicole, Vegard Skirbekk and Rudolf Winter-Ebmer (2014), 'Does education improve cognitive performance four decades after school completion?', Demography 51(2), 619-643.

Skirbekk, Vegard (2008), 'Fertility trends by social status', Demographic Research 18(5), 145180.

Smith, Ken R., Geraldine P. Mineau and Lee L. Bean (2002), 'Fertility and post-reproductive longevity', Biodemography and Social Biology 49, 185-205.

Staiger, Douglas and James H. Stock (1997), 'Instrumental Variables Regression With Weak Instruments', Econometrica 65, 557-586. 
Strauss, John and Duncan Thomas (1995), Human resources: Empirical modeling of household and family decisions, in J.Behrman and T. N.Srinivasan, eds, 'The Handbook of Development Economics', Vol. 3A, Elsevier, pp. 1883-2023.

Thevenon, Olivier (2010), Macro-level database on fertility and policies supporting families with children in European and OECD countries, Report, OECD policy division.

Thomas, Duncan, John Strauss and Maria-Helena Henriques (1991), 'How does mother's education affect child height?', Journal of Human Resources 26(2), 183-211. 


\section{Tables}

Table 1: Compulsory schooling reforms in England and Continental Europe

\begin{tabular}{lccc}
\hline \hline Reform & Schooling & School leaving age & Pivotal Cohort \\
\hline England 1947 & 9 to 10 & 14 to 15 & 1933 \\
Continental Europe & & & \\
Austria 1962/66 & 8 to 9 & 14 to 15 & 1951 \\
Denmark 1958 & 4 to 7 & 11 to 14 & 1947 \\
Denmark 1971 & 7 to 9 & 14 to 16 & 1957 \\
France 1936 & 7 to 8 & 13 to 14 & 1923 \\
France 1959/67 & 8 to 10 & 14 to 16 & 1953 \\
Italy 1963 & 5 to 8 & 11 to 14 & 1949 \\
Netherlands 1950 & 7 to 8 & 13 to 14 & 1936 \\
Netherlands $1971 / 75$ & 8 to $9 / 10$ & 14 to $15 / 16$ & $1957 / 59$ \\
\hline \hline
\end{tabular}

Notes: For further details on the reforms and the derivation of the pivotal cohorts see Appendix A.1. 


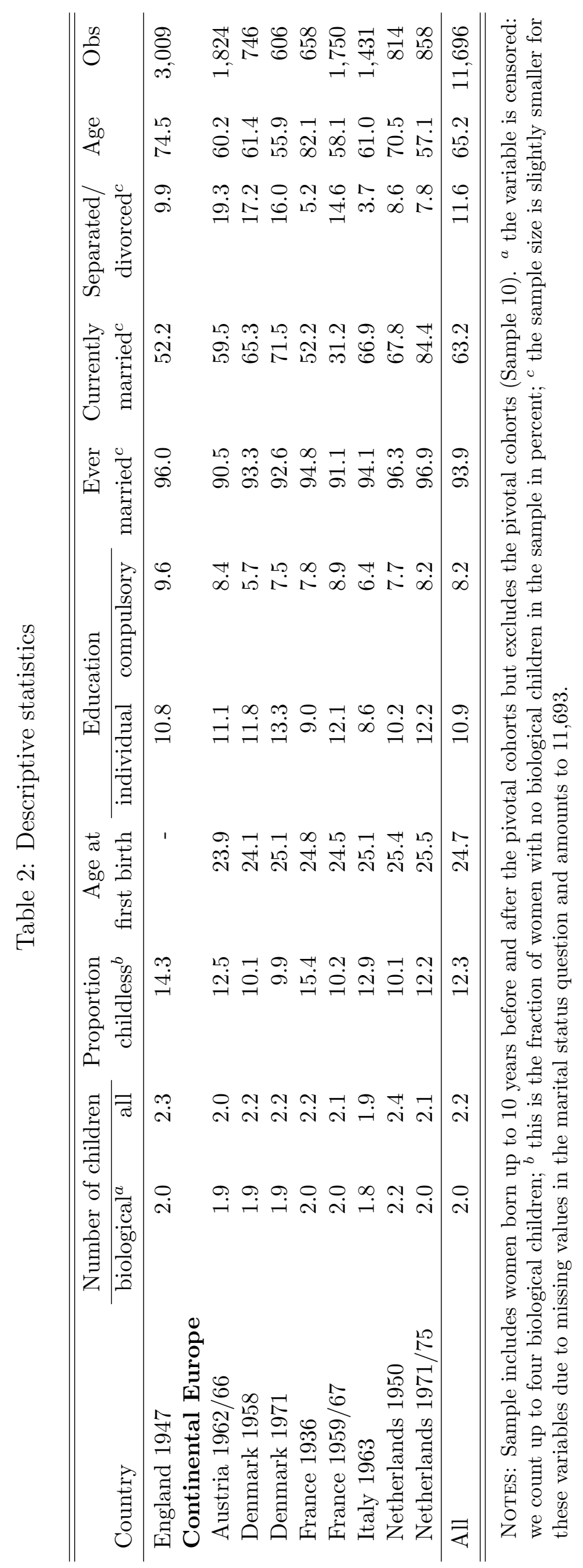


Table 3: Baseline results

\begin{tabular}{|c|c|c|c|c|c|c|}
\hline & \multicolumn{2}{|c|}{ England } & \multicolumn{2}{|c|}{ Continent } & \multicolumn{2}{|c|}{ Continent with c-f-e $\mathrm{e}^{a}$} \\
\hline & Sample 10 & Sample 7 & Sample 10 & Sample 7 & Sample 10 & Sample 7 \\
\hline \multicolumn{7}{|c|}{ A: \# biological children } \\
\hline OLS & $\begin{array}{l}-0.038 \\
(0.012)^{* * *}\end{array}$ & $\begin{array}{l}-0.047 \\
(0.014)^{* * *}\end{array}$ & $\begin{array}{l}-0.037 \\
(0.004)^{* * *}\end{array}$ & $\begin{array}{l}-0.038 \\
(0.005)^{* * *}\end{array}$ & $\begin{array}{l}-0.037 \\
(0.004) * * *\end{array}$ & $\begin{array}{l}-0.038 \\
(0.005)^{* * *}\end{array}$ \\
\hline 2SLS & $\begin{array}{l}-0.282 \\
(0.072)^{* * *}\end{array}$ & $\begin{array}{l}-0.307 \\
(0.088) * * *\end{array}$ & $\begin{array}{l}0.211 \\
(0.074)^{* * *}\end{array}$ & $\begin{array}{l}0.291 \\
(0.081)^{* * *}\end{array}$ & $\begin{array}{l}0.302 \\
(0.108)^{* * *}\end{array}$ & $\begin{array}{l}0.264 \\
(0.105)^{* *}\end{array}$ \\
\hline Reduced Form & $\begin{array}{l}-0.196 \\
(0.068)^{* * *}\end{array}$ & $\begin{array}{l}-0.214 \\
(0.087)^{* *}\end{array}$ & $\begin{array}{l}0.059 \\
(0.017)^{* * *}\end{array}$ & $\begin{array}{l}0.090 \\
(0.020)^{* * *}\end{array}$ & $\begin{array}{l}0.081 \\
(0.022)^{* * *}\end{array}$ & $\begin{array}{l}0.079 \\
(0.026)^{* * *}\end{array}$ \\
\hline \multicolumn{7}{|c|}{ B: Childlessness } \\
\hline OLS & $\begin{array}{l}0.012 \\
(0.004)^{* * *}\end{array}$ & $\begin{array}{l}0.016 \\
(0.005)^{* * *}\end{array}$ & $\begin{array}{l}0.007 \\
(0.001)^{* * *}\end{array}$ & $\begin{array}{l}0.007 \\
(0.001)^{* * *}\end{array}$ & $\begin{array}{l}0.007 \\
(0.001)^{* * *}\end{array}$ & $\begin{array}{l}0.007 \\
(0.001)^{* * *}\end{array}$ \\
\hline 2SLS & $\begin{array}{c}0.032 \\
(0.036)\end{array}$ & $\begin{array}{c}0.066 \\
(0.036)^{*}\end{array}$ & $\begin{array}{l}-0.045 \\
(0.025)^{*}\end{array}$ & $\begin{array}{l}-0.082 \\
(0.030)^{* * *}\end{array}$ & $\begin{array}{l}-0.093 \\
(0.035) * * *\end{array}$ & $\begin{array}{l}-0.111 \\
(0.038)^{* * *}\end{array}$ \\
\hline Reduced Form & $\begin{array}{c}0.022 \\
(0.028)\end{array}$ & $\begin{array}{c}0.046 \\
(0.030)\end{array}$ & $\begin{array}{l}-0.013 \\
(0.006) *\end{array}$ & $\begin{array}{l}-0.025 \\
(0.007)^{* * *}\end{array}$ & $\begin{array}{l}-0.025 \\
(0.007)^{* * *}\end{array}$ & $\begin{array}{l}-0.033 \\
(0.008)^{* * *}\end{array}$ \\
\hline First Stage & $\begin{array}{c}0.697 \\
(0.130)^{* * *}\end{array}$ & $\begin{array}{c}0.698 \\
(0.159)^{* * *}\end{array}$ & $\begin{array}{l}0.280 \\
(0.060)^{* * *}\end{array}$ & $\begin{array}{c}0.311 \\
(0.062)^{* * *}\end{array}$ & $\begin{array}{l}0.269 \\
(0.061)^{* * *}\end{array}$ & $\begin{array}{l}0.299 \\
(0.067)^{* * *}\end{array}$ \\
\hline F-Statistics & 28.68 & 19.20 & 21.67 & 25.31 & 19.34 & 20.02 \\
\hline Observations & 3,009 & 2,150 & 8,686 & 6,401 & 8,686 & 6,401 \\
\hline
\end{tabular}

NOTES: Each coefficient represents a separate linear regression. Linear trends in birth cohorts that differ before and after the reforms are included in all models and are country-reform-specific in the regressions for Continental Europe. These regressions also control for country-reform-fixed effects. Indicators for the interview year, foreign born and proxy interviews are included in all regressions. Heteroscedasticity and cluster-robust standard errors in parentheses (clusters are birth cohorts in England and country-reform-cohort in Continental Europe). ${ }^{* * *},{ }^{* *}$ and $*$ indicate statistical significance at the 1-percent, 5-percent and 10-percent level. ${ }^{a}$ cohort-fixed effects are included in these models. 
Table 4: Mechanisms

\begin{tabular}{|c|c|c|c|c|c|c|}
\hline & \multicolumn{2}{|c|}{ England } & \multicolumn{2}{|c|}{ Continent } & \multicolumn{2}{|c|}{ Continent with c-f-e $\mathrm{e}^{a}$} \\
\hline & Sample 10 & Sample 7 & Sample 10 & Sample 7 & Sample 10 & Sample 7 \\
\hline \multicolumn{7}{|c|}{ A: Marriage outcomes } \\
\hline \multicolumn{7}{|c|}{ Ever married } \\
\hline OLS & $\begin{array}{l}-0.011 \\
(0.002)^{* * *}\end{array}$ & $\begin{array}{l}-0.013 \\
(0.002)^{* * *}\end{array}$ & $\begin{array}{l}-0.005 \\
(0.001)^{* * *}\end{array}$ & $\begin{array}{l}-0.005 \\
(0.001)^{* * *}\end{array}$ & $\begin{array}{l}-0.005 \\
(0.001)^{* * *}\end{array}$ & $\begin{array}{l}-0.005 \\
(0.001)^{* * *}\end{array}$ \\
\hline 2SLS & $\begin{array}{l}-0.015 \\
(0.015)\end{array}$ & $\begin{array}{l}-0.065 \\
(0.025)^{* *}\end{array}$ & $\begin{array}{c}0.022 \\
(0.020)\end{array}$ & $\begin{array}{c}0.034 \\
(0.020)^{*}\end{array}$ & $\begin{array}{l}0.056 \\
(0.026)^{* *}\end{array}$ & $\begin{array}{l}0.055 \\
(0.022)^{* *}\end{array}$ \\
\hline \multicolumn{7}{|c|}{ Currently married } \\
\hline OLS & $\begin{array}{c}0.004 \\
(0.004)\end{array}$ & $\begin{array}{l}0.008 \\
(0.004)^{*}\end{array}$ & $\begin{array}{l}-0.003 \\
(0.002)^{* *}\end{array}$ & $\begin{array}{l}-0.004 \\
(0.002)^{* *}\end{array}$ & $\begin{array}{l}-0.003 \\
(0.002)^{* *}\end{array}$ & $\begin{array}{l}-0.004 \\
(0.002)^{* *}\end{array}$ \\
\hline 2SLS & $\begin{array}{l}-0.099 \\
(0.058)^{*}\end{array}$ & $\begin{array}{l}-0.104 \\
(0.069)\end{array}$ & $\begin{array}{c}0.030 \\
(0.031)\end{array}$ & $\begin{array}{c}0.054 \\
(0.030)^{*}\end{array}$ & $\begin{array}{l}0.079 \\
(0.040)^{* *}\end{array}$ & $\begin{array}{c}0.064 \\
(0.038)^{*}\end{array}$ \\
\hline \multicolumn{7}{|c|}{ Separated/divorced } \\
\hline OLS & $\begin{array}{l}-0.001 \\
(0.003)\end{array}$ & $\begin{array}{l}-0.004 \\
(0.003)\end{array}$ & $\begin{array}{l}0.004 \\
(0.001)^{* * *}\end{array}$ & $\begin{array}{l}0.004 \\
(0.001)^{* * *}\end{array}$ & $\begin{array}{l}0.004 \\
(0.001)^{* * *}\end{array}$ & $\begin{array}{l}0.004 \\
(0.001)^{* * *}\end{array}$ \\
\hline 2SLS & $\begin{array}{c}0.018 \\
(0.027)\end{array}$ & $\begin{array}{l}-0.000 \\
(0.035)\end{array}$ & $\begin{array}{l}-0.018 \\
(0.023)\end{array}$ & $\begin{array}{l}-0.010 \\
(0.022)\end{array}$ & $\begin{array}{l}-0.012 \\
(0.023)\end{array}$ & $\begin{array}{c}0.004 \\
(0.024)\end{array}$ \\
\hline Observations & 3,009 & 2,150 & 8,683 & 6,398 & 8,683 & 6,398 \\
\hline \multicolumn{7}{|c|}{$\begin{array}{l}\text { B: Quality of partner } \\
\text { Years of education of partner }\end{array}$} \\
\hline OLS & $\begin{array}{l}0.633 \\
(0.026)^{* * *}\end{array}$ & $\begin{array}{l}0.618 \\
(0.032)^{* * *}\end{array}$ & $\begin{array}{l}0.556 \\
(0.017)^{* * *}\end{array}$ & $\begin{array}{l}0.551 \\
(0.019)^{* * *}\end{array}$ & $\begin{array}{l}0.555 \\
(0.017)^{* * *}\end{array}$ & $\begin{array}{l}0.551 \\
(0.019)^{* * *}\end{array}$ \\
\hline 2SLS & $\begin{array}{l}0.563 \\
(0.246)^{* *} \\
\end{array}$ & $\begin{array}{l}0.574 \\
(0.286)^{* *} \\
\end{array}$ & $\begin{array}{l}0.721 \\
(0.272)^{* * *} \\
\end{array}$ & $\begin{array}{c}0.445 \\
(0.312) \\
\end{array}$ & $\begin{array}{c}0.462 \\
(0.395) \\
\end{array}$ & $\begin{array}{c}0.365 \\
(0.507)\end{array}$ \\
\hline Observations & 1,497 & 1,036 & 6,492 & 4,756 & 6,492 & 4,756 \\
\hline
\end{tabular}

Notes: Each coefficient represents a separate linear regression. Linear trends in birth cohorts that differ before and after the reforms are included in all models and are country-reform-specific in the regressions for Continental Europe. These regressions also control for country-reform-fixed effects. Indicators for the interview year, foreign born and proxy interviews are included in all regressions. Heteroscedasticity and cluster-robust standard errors in parentheses (clusters are birth cohorts in England and country-reform-cohort in Continental Europe). ***, ** and * indicate statistical significance at the 1-percent, 5-percent and 10-percent level. ${ }^{a}$ cohort-fixed effects are included in these models; ${ }^{b}$ this variable is only available for married women in England and ever married women in Continental Europe. 
Table 5: Selective mortality

\begin{tabular}{|c|c|c|c|c|c|c|}
\hline & \multicolumn{2}{|c|}{ England } & \multicolumn{2}{|c|}{ Continent } & \multicolumn{2}{|c|}{ Continent with c-f-e ${ }^{a}$} \\
\hline & Sample 10 & Sample 7 & Sample 10 & Sample 7 & Sample 10 & Sample 7 \\
\hline \multicolumn{7}{|c|}{ A: \# biological children } \\
\hline LE control ${ }^{b}$ & $\begin{array}{l}-0.274 \\
(0.071)^{* * *}\end{array}$ & $\begin{array}{l}-0.302 \\
(0.089)^{* * *}\end{array}$ & $\begin{array}{l}0.233 \\
(0.080)^{* * *}\end{array}$ & $\begin{array}{l}0.318 \\
(0.102)^{* * *}\end{array}$ & $\begin{array}{l}0.314 \\
(0.117)^{* * *}\end{array}$ & $\begin{array}{c}0.264 \\
(0.105)^{* *}\end{array}$ \\
\hline LE weight ${ }^{c}$ & $\begin{array}{l}-0.215 \\
(0.091)^{* *}\end{array}$ & $\begin{array}{l}-0.327 \\
(0.107)^{* * *}\end{array}$ & $\begin{array}{l}0.175 \\
(0.066)^{* * *}\end{array}$ & $\begin{array}{l}0.279 \\
(0.084)^{* * *}\end{array}$ & $\begin{array}{l}0.292 \\
(0.105)^{* * *}\end{array}$ & $\begin{array}{l}0.286 \\
(0.133)^{* *}\end{array}$ \\
\hline \multicolumn{3}{|c|}{ Recent cohorts $^{d}$} & $\begin{array}{c}0.184 \\
(0.066)^{* * *}\end{array}$ & $\begin{array}{l}0.280 \\
(0.082)^{* * *}\end{array}$ & $\begin{array}{l}0.301 \\
(0.104)^{* * *}\end{array}$ & $\begin{array}{c}0.233 \\
(0.113)^{* *}\end{array}$ \\
\hline \multicolumn{7}{|c|}{ B: childlessness } \\
\hline LE control & $\begin{array}{c}0.038 \\
(0.034)\end{array}$ & $\begin{array}{c}0.066 \\
(0.038)^{*}\end{array}$ & $\begin{array}{l}-0.058 \\
(0.027)^{* *}\end{array}$ & $\begin{array}{l}-0.102 \\
(0.037)^{* * *}\end{array}$ & $\begin{array}{l}-0.099 \\
(0.038)^{* * *}\end{array}$ & $\begin{array}{l}-0.118 \\
(0.037)^{* * *}\end{array}$ \\
\hline LE weight & $\begin{array}{c}0.039 \\
(0.031)\end{array}$ & $\begin{array}{c}0.087 \\
(0.046)^{*}\end{array}$ & $\begin{array}{l}-0.050 \\
(0.025)^{* *}\end{array}$ & $\begin{array}{l}-0.080 \\
(0.032)^{* *}\end{array}$ & $\begin{array}{l}-0.082 \\
(0.032)^{* *}\end{array}$ & $\begin{array}{l}-0.111 \\
(0.048)^{* *}\end{array}$ \\
\hline \multicolumn{3}{|c|}{ Recent cohorts } & $\begin{array}{l}-0.041 \\
(0.024)^{*}\end{array}$ & $\begin{array}{l}-0.075 \\
(0.030)^{* *}\end{array}$ & $\begin{array}{l}-0.096 \\
(0.034)^{* * *}\end{array}$ & $\begin{array}{l}-0.105 \\
(0.041)^{* *}\end{array}$ \\
\hline
\end{tabular}

NOTES: Each coefficient represents a separate linear regression. Linear trends in birth cohorts that differ before and after the reforms are included in all models and are country-reform-specific in the regressions for Continental Europe. These regressions also control for country-reform-fixed effects. Indicators for the interview year, foreign born and proxy interviews are included in all regressions. Heteroscedasticity and cluster-robust standard errors in parentheses (clusters are birth cohorts in England and country-reform-cohort in Continental Europe). ${ }^{* * *},{ }^{* *}$ and ${ }^{*}$ indicate statistical significance at the 1-percent, 5-percent and 10-percent level. ${ }^{a}$ cohort-fixed effects are included in these models; ${ }^{b}$ life-expectancy at birth is included as control variable; ${ }^{c}$ life-expectancy is used to weight the observations; ${ }^{d}$ only birth cohorts born from 1940 considered, note that the reforms in France 1936 and Netherlands 1950 can not be included, the number of observations is 7,077/5,399 for Sample 10/7. 
Table 6: Selective mortality of children

\begin{tabular}{|c|c|c|c|c|c|c|}
\hline & \multicolumn{2}{|c|}{ England } & \multicolumn{2}{|c|}{ Continent } & \multicolumn{2}{|c|}{ Continent with c-f-e $\mathrm{e}^{a}$} \\
\hline & Sample 10 & Sample 7 & Sample 10 & Sample 7 & Sample 10 & Sample 7 \\
\hline \multicolumn{7}{|c|}{ Individuals with retrospective interview } \\
\hline Childless (at interview) & $\begin{array}{c}0.035 \\
(0.036)\end{array}$ & $\begin{array}{l}0.085 \\
(0.031) * * *\end{array}$ & $\begin{array}{l}-0.141 \\
(0.127)\end{array}$ & $\begin{array}{l}-0.173 \\
(0.124)\end{array}$ & $\begin{array}{l}-0.466 \\
(0.685)\end{array}$ & $\begin{array}{l}-0.263 \\
(0.350)\end{array}$ \\
\hline Mean & {$[0.145]$} & {$[0.137]$} & {$[0.123]$} & {$[0.129]$} & {$[0.123]$} & {$[0.129]$} \\
\hline Never had children & $\begin{array}{c}0.034 \\
(0.030)\end{array}$ & $\begin{array}{l}0.088 \\
(0.028) * * *\end{array}$ & $\begin{array}{l}-0.142 \\
(0.131)\end{array}$ & $\begin{array}{l}-0.184 \\
(0.132)\end{array}$ & $\begin{array}{l}-0.497 \\
(0.746)\end{array}$ & $\begin{array}{l}-0.224 \\
(0.320)\end{array}$ \\
\hline Mean & {$[0.135]$} & {$[0.130]$} & {$[0.116]$} & {$[0.121]$} & {$[0.116]$} & {$[0.121]$} \\
\hline First Stage & $\begin{array}{c}0.965 \\
(0.137)^{* * *}\end{array}$ & $\begin{array}{l}0.929 \\
(0.128)^{* * *}\end{array}$ & $\begin{array}{c}0.172 \\
(0.124)\end{array}$ & $\begin{array}{c}0.230 \\
(0.144)\end{array}$ & $\begin{array}{c}0.113 \\
(0.166)\end{array}$ & $\begin{array}{c}0.160 \\
(0.203)\end{array}$ \\
\hline F-Statistics & 49.66 & 53.03 & 1.92 & 2.54 & 0.47 & 0.62 \\
\hline Observations $^{a}$ & 1,784 & 1,289 & 2,995 & 2,221 & 2,995 & 2,221 \\
\hline
\end{tabular}

Notes: Each coefficient represents a separate linear regression. Linear trends in birth cohorts that differ before and after the reforms are included in all models and are country-reform-specific in the regressions for Continental Europe. These regressions also control for country-reform-fixed effects. Indicators for the interview year, foreign born and proxy interviews are included in all regressions. Heteroscedasticity and cluster-robust standard errors in parentheses (clusters are birth cohorts in England and country-reform-cohort in Continental Europe). ***, ** and * indicate statistical significance at the 1-percent, 5-percent and 10-percent level. ${ }^{a}$ cohort-fixed effects are included in these models. 


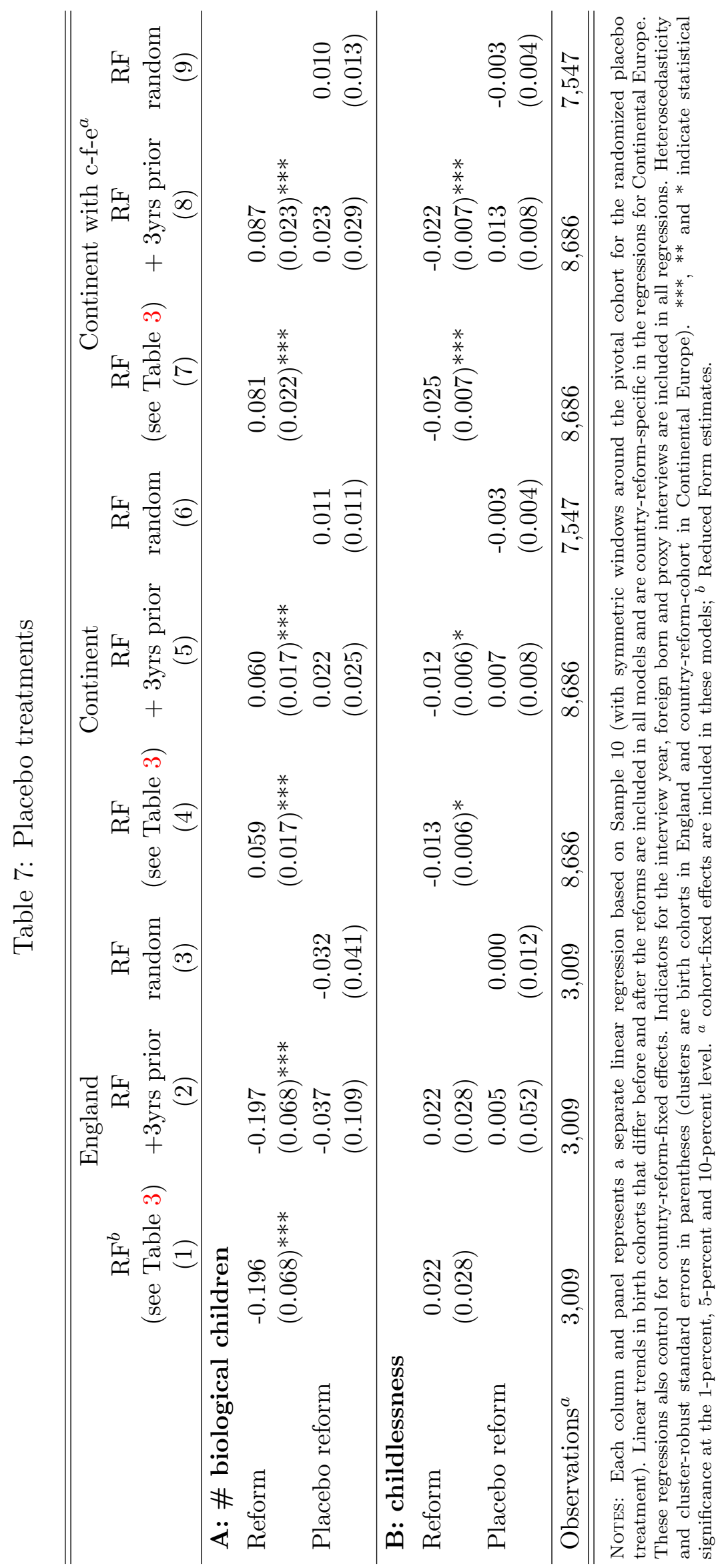


Table 8: Tobit regressions (right censoring at 4 and corner solution at 0 )

\begin{tabular}{lllllll}
\hline \hline & \multicolumn{2}{c}{ England } & \multicolumn{2}{c}{ Continent } & \multicolumn{2}{c}{ Continent with c-f-e } \\
& Tobit & IV-Tobit & Tobit & IV-Tobit & Tobit & IV-Tobit \\
\hline Coefficient & -0.053 & -0.355 & -0.047 & 0.278 & -0.047 & 0.415 \\
& $(0.016)^{* * *}$ & $(0.110)^{* *}$ & $(0.005)^{* * *}$ & $(0.096)^{* * *}$ & $(0.005)^{* * *}$ & $(0.143)^{* * *}$ \\
\hline Average Partial & Effects $^{b}$ on & & & & & \\
$\operatorname{Prob}[Y=0]$ & 0.006 & 0.041 & 0.005 & -0.036 & 0.005 & -0.051 \\
& $(0.002)^{* * *}$ & $(0.012)^{* * *}$ & $(0.001)^{* * *}$ & $(0.013)^{* * *}$ & $(0.001)^{* * *}$ & $(0.017)^{* * *}$ \\
$E[Y \mid Y>0]$ & -0.037 & -0.242 & -0.035 & 0.182 & -0.036 & 0.253 \\
& $(0.011)^{* * *}$ & $(0.076)^{* * *}$ & $(0.004)^{* * *}$ & $(0.062)^{* * *}$ & $(0.004)^{* * *}$ & $(0.086)^{* *}$ \\
$E[Y \mid 1<Y<4]$ & -0.014 & -0.081 & -0.016 & 0.060 & -0.016 & 0.066 \\
& $(0.004)^{* * *}$ & $(0.024)^{* * *}$ & $(0.002)^{* * *}$ & $(0.020)^{* * *}$ & $(0.002)^{* * *}$ & $(0.021)^{* *}$ \\
\hline \hline
\end{tabular}

Notes: Each column represents a separate regression based on Sample 10. Tobit: education is treated as exogenous, IV-Tobit: education is treated as endogenous. Linear trends in birth cohorts that differ before and after the reforms are included in all models and are country-reform-specific in the regressions for Continental Europe. These regressions also control for country-reform-fixed effects. Indicators for the interview year, foreign born and proxy interviews are included in all regressions. Heteroscedasticity and cluster-robust standard errors in parentheses (clusters are birth cohorts in England and country-reform-cohort in Continental Europe). ***, ** and $*$ indicate statistical significance at the 1-percent, 5-percent and 10-percent level. ${ }^{a}$ cohort-fixed effects are included in these models; ${ }^{b}$ Average Partial Effects are calculated at mean values of covariates in the sample.

Table 9: Sensitivity to sample and trend-specification

\begin{tabular}{lllllll}
\hline \hline & \multicolumn{2}{c}{ England $^{b}$} & \multicolumn{2}{c}{ Continent } & \multicolumn{2}{c}{ Continent with c-f-e $^{a}$} \\
& Symmetric $^{b}$ & Quadratic $^{c}$ & Symmetric & Quadratic & Symmetric & Quadratic \\
\hline 2SLS & & & & & & \\
\# biological children & -0.282 & -0.284 & 0.189 & 0.178 & 0.357 & 0.268 \\
& $(0.072)^{* * *}$ & $(0.076)^{* * *}$ & $(0.064)^{* * *}$ & $(0.069)^{* *}$ & $(0.134)^{* * *}$ & $(0.125)^{* *}$ \\
Childlessness & 0.032 & 0.029 & -0.042 & -0.040 & -0.111 & -0.082 \\
& $(0.036)$ & $(0.040)$ & $(0.022)^{*}$ & $(0.024)^{*}$ & $(0.042)^{* * *}$ & $(0.040)^{* *}$ \\
\hline First Stage & 0.697 & 0.685 & 0.309 & 0.301 & 0.256 & 0.258 \\
& $(0.130)^{* * *}$ & $(0.132)^{* * *}$ & $(0.060)^{* * *}$ & $(0.062)^{* * *}$ & $(0.062)^{* * *}$ & $(0.063)^{* * *}$ \\
\hline F-Statistics & 28.68 & 27.14 & 26.61 & 23.61 & 16.96 & 16.81 \\
Observations $^{a}$ & 3,009 & 3,009 & 7,547 & 8,686 & 7,547 & 8,686 \\
\hline \hline
\end{tabular}

Notes: Each coefficient represents a separate linear regression. Trends in birth cohorts are included in all models and are country-reform-specific in the regressions for Continental Europe. These regressions also control for country-reform-fixed effects. Indicators for the interview year, foreign born and proxy interviews are included in all regressions. Heteroscedasticity and cluster-robust standard errors in parentheses (clusters are birth cohorts in England and country-reform-cohort in Continental Europe). ${ }^{* * *},{ }^{* *}$ and $*$ indicate statistical significance at the 1-percent, 5-percent and 10-percent level. $a$ cohort-fixed effects are included in these models. ${ }^{b}$ sample is symmetric around the pivotal cohort, i.e. it includes the same number of cohorts before and after with a maximum of 10; the trends in birth cohorts are linear and differ before and after the pivotal cohort. ${ }^{c}$ regressions are based on Sample 10; trends in birth cohorts are quadratic and do not differ before and after the pivotal cohort. 


\section{$9 \quad$ Figures}
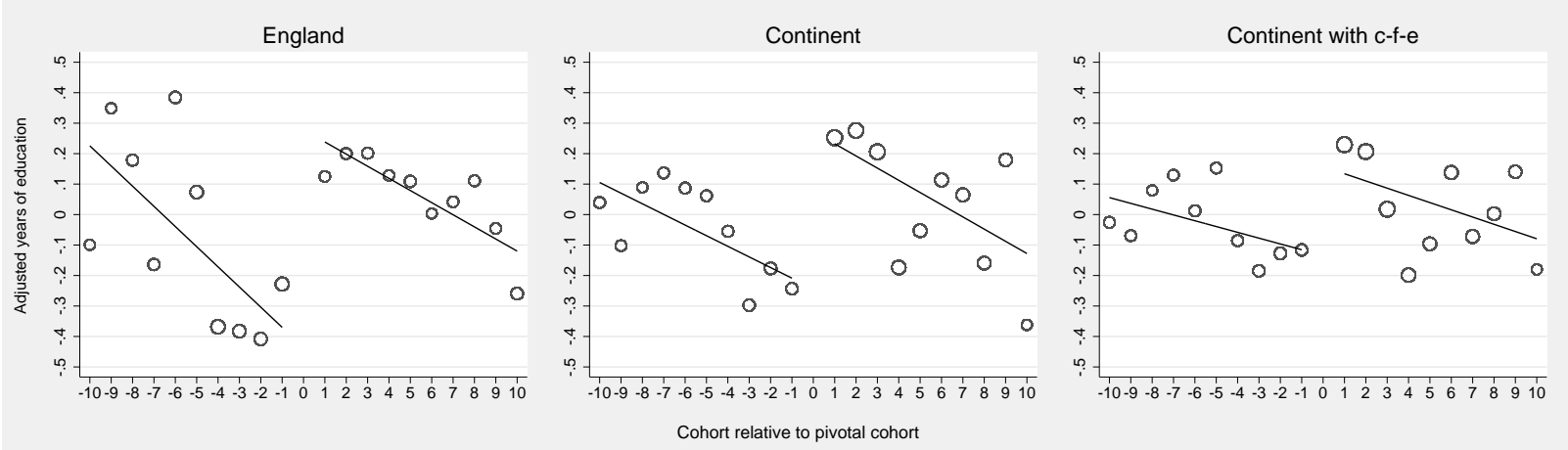

Figure 1: First Stage (adjusted)

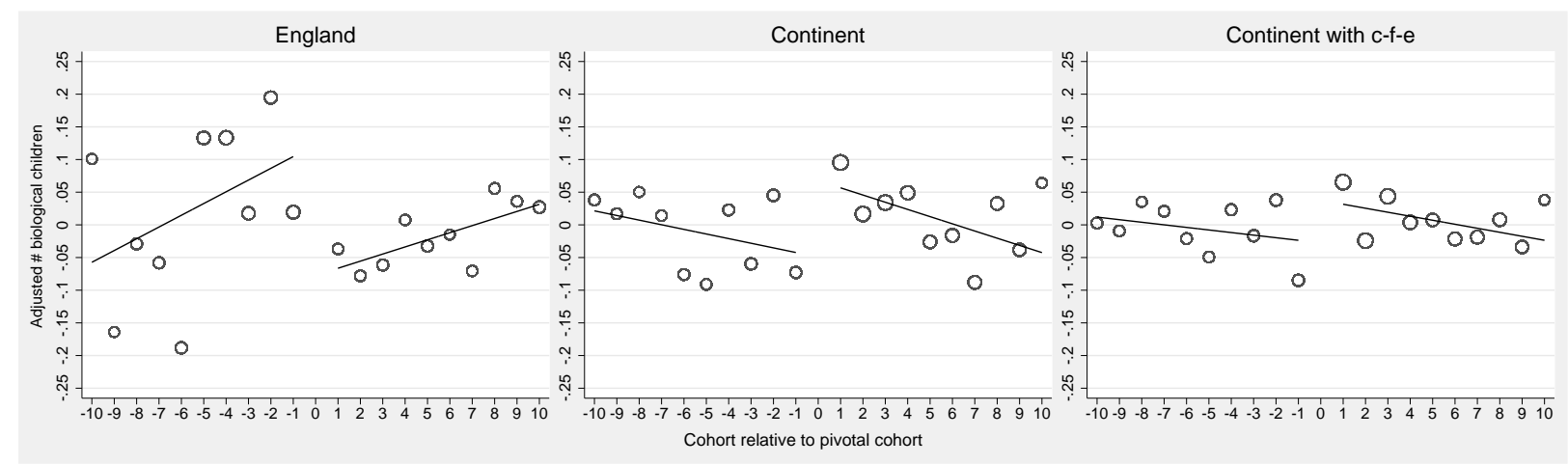

Figure 2: Reduced form (adjusted) - \# biological children
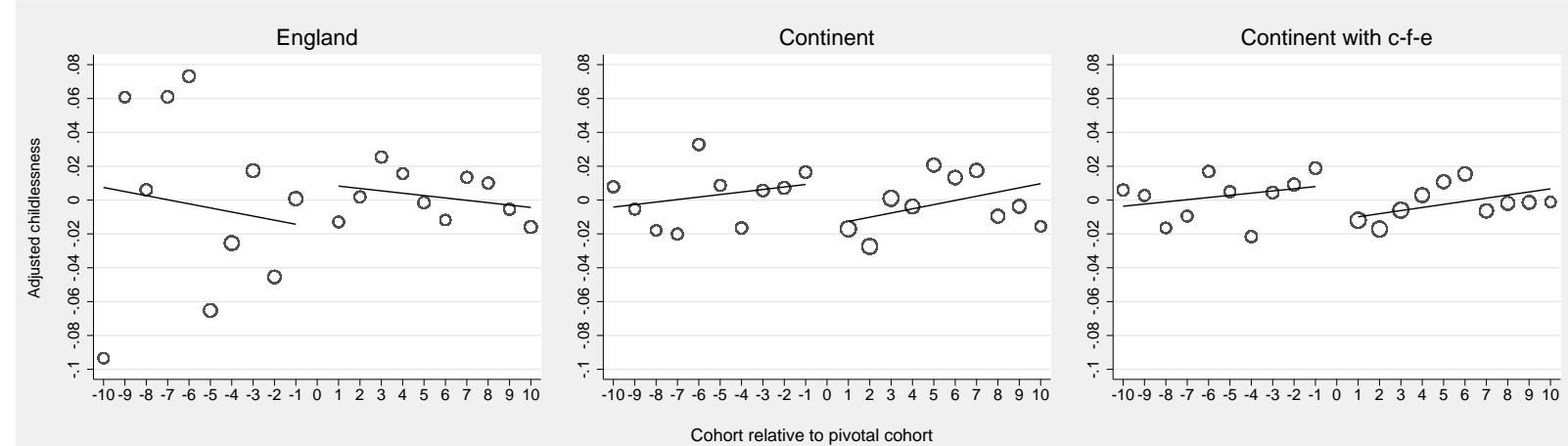

Figure 3: Reduced form (adjusted) - childlessness 


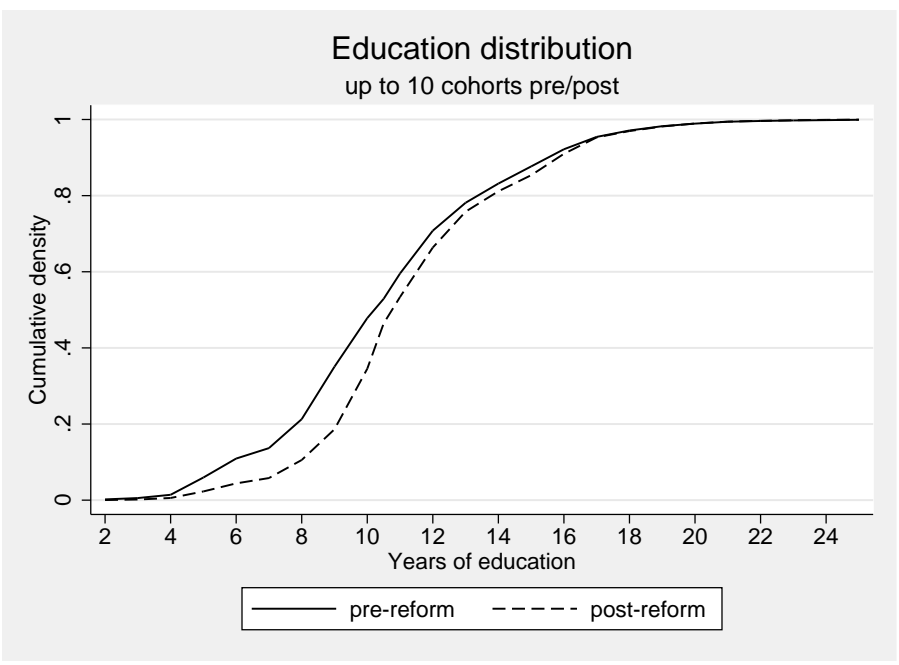

Figure 4: Education distribution before and after 


\section{A Appendix}

\section{A.1 Educational Reforms in Europe}

In this section, we briefly describe the compulsory schooling reforms we are using in this study. The choice of reforms differs somewhat from Brunello et al. (2009) because the individuals in our data-set are of age 45 or older at the time of the interviews in 2004-20011. Thus, we are not able to consider more recent reforms in this study.

Austria 1962/66 In 1962 a federal act was passed that increased compulsory schooling from 8 to 9 years. The law came into effect on September 1, 1966 (Federal Act of Compulsory Schooling No. 241,'Schulpflichtgesetz', 1962, Paragraphs 3 and 25). Pupils who were 14 years old (or younger) at that time had to attend school for an additional year. Since compulsory education starts at the age of 6 and the cut-off date for school-entry is September 1, (mostly) individuals born between September and December 1951 were the first ones affected by the reform. Thus, the pivotal cohort is 1951. Note that the fact that the law came into effect only four years after it was passed has been missed in many previous studies.

Denmark 1958 Compulsory education has been increased in 1958 by 3 years, from 4 to 7 years of schooling. The school year started in April at that time and all children who turned 7 during the calender year enrolled in school. Thus, the cohort born in 1947 is the first one you was potentially affected by the new legislation. These children turned 7 in 1954 and finished 4 years of schooling in 1958 (Garrouste, 2010; Gathmann et al., 2014). Note that the definition of the pivotal cohort varies in the literature to some extent and is 1945 in Arendt (2005) and 1946 in Arendt (2008). Moreover, Fonseca and Zheng (2011) uses the 1958 reform in a cross-country study and assumes a one-year increase in 'actual' education from 7 to 8 years due to the fact that many children already had more years of education prior to the reform. As Arendt (2005) describes in his paper in more detail, the reform mainly enhanced equality of opportunity by abolishing early sorting mechanisms and aligning different types of middle schools. While this is a possible way to proceed, we stick to the legal definition of compulsory schooling in this paper.

Denmark 1971 In 1971 compulsory schooling was increased by 2 years, from 7 to 9 years of schooling. The first cohort affected by this reform was born in 1957. This cohort enrolled in school in 1964 and finished 7 years of schooling in 1971 (Brunello et al., 2009; Fort, 2006; Garrouste, 2010; Gathmann et al., 2014; Murtin and Viarengo, 2011). As described in Gathmann et al. (2014) a new act on the Folkeskole was adopted in 1975, which introduced a comprehensive primary and lower secondary school, which has been exploited by Arendt (2005).

England 1947 Two major compulsory schooling reforms were implemented in the England and Wales in 1947 and 1973. In this study, we consider only the first reform because of datalimitations. The reform in 1947 increased the minimum school leaving age from 14 to 15. (1944 Education Act). Since the school-entry age is 5 in the UK, compulsory schooling was increased from 9 to 10 years. Pupils who were 14 years old (or younger) on April $1^{\text {st }}, 1947$ were affected by this reform, i.e. the cohort 1933 was the first one (partly) affected by the reform (Devereux 
and Hart, 2010; Gathmann et al., 2014; Harmon and Walker, 1995; Murtin and Viarengo, 2011).

France 1936 In 1936, compulsory schooling was increased from 7 to 8 years in France, indicating an increase in the mean school leaving age form 13 to 14 . The first pupils who were affected by the reform were those aged 13 in 1936, thus individuals who were born in 1923 (Albouya and Lequien, 2009; Fort, 2006; Garrouste, 2010; Gathmann et al., 2014).

France 1959/67 Compulsory schooling was further raised from 8 to 10 years (age 14 to 16 ) in 1959. After a long transition period, this reform came into effect in 1967. The first cohort who was affected by this reform was the cohort born in 1953 (Brunello et al., 2009; Fort, 2006; Garrouste, 2010; Gathmann et al., 2014; Grenet, 2013; Murtin and Viarengo, 2011).

Italy 1963 In 1963 junior high school became mandatory in Italy, which increased compulsory years of schooling by 3 years (from 5 to 8 years). School starts at the age of 6 . According to Fort (2006), the first cohort potentially affected by this reform is the cohort born in 1949 (Brunello et al., 2009; Fort, 2009; Gathmann et al., 2014; Murtin and Viarengo, 2011).

Netherlands 1950 In 1950 compulsory schooling was increased from 7 to 8 years. The school entry age was 6 , so under the new law individuals were meant to stay in school until age 14 . Those who were born in 1936 were the first ones potentially affected by the new law (Gathmann et al., 2014; Levin and Plug, 1999; Murtin and Viarengo, 2011).

Netherlands 1971/75 Two further education reforms were implemented in 1971 and 1975. Compulsory schooling was first increased from 8 to 9 years in 1971 and further raised to 10 years in 1975. The pivotal cohort for the first reform is the cohort born in 1957 and for the second reform it is the cohort born in 1959 (Brunello et al., 2009; Fort, 2006; Gathmann et al., 2014; Levin and Plug, 1999; Murtin and Viarengo, 2011). Because of the narrow timing of these two reforms and the fact that we observe only cohorts until 1960 in our data-set for the Netherlands, we decided to collapse these two reforms. 
A.2 Additional Tables and Figures 


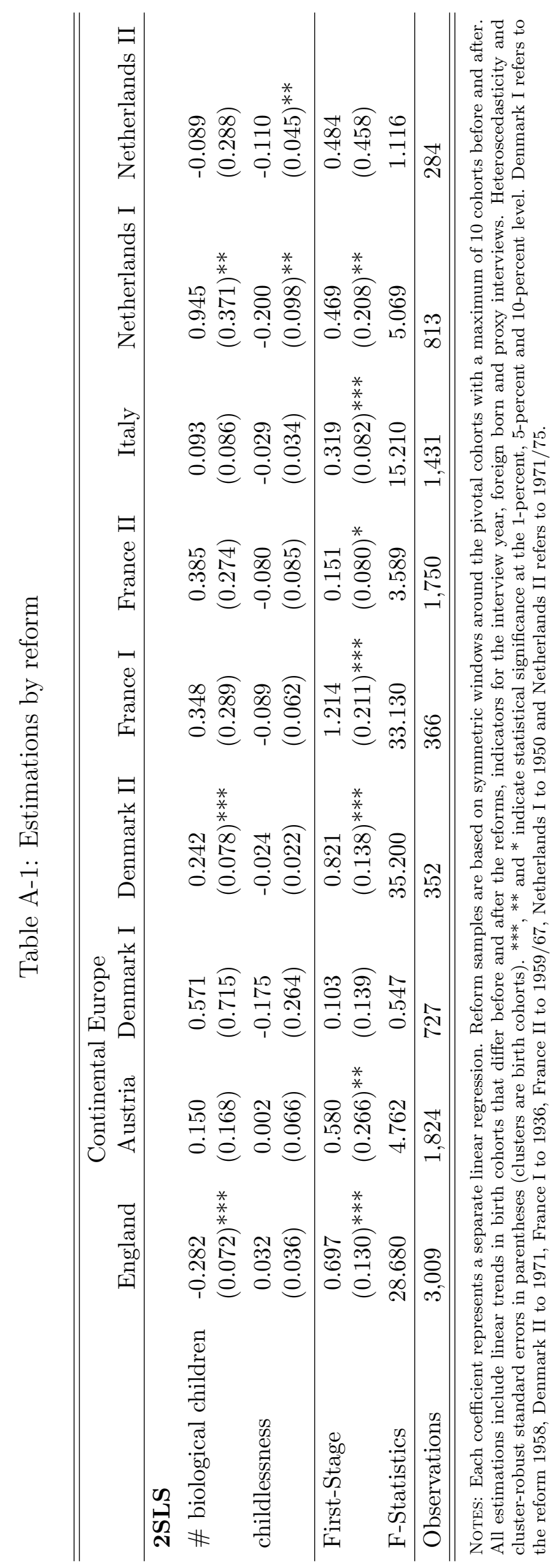




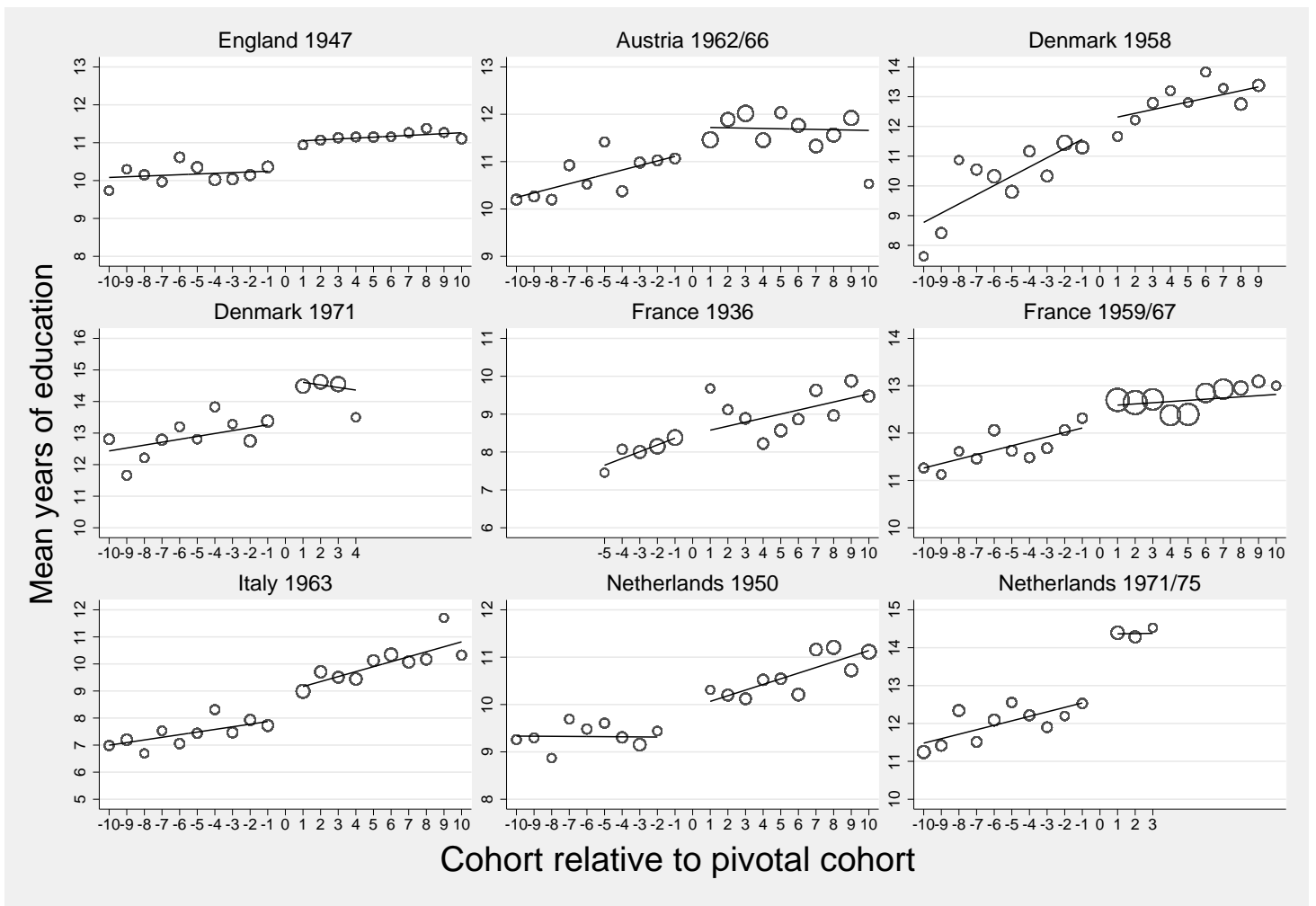

Figure A-1: First Stages by reform 


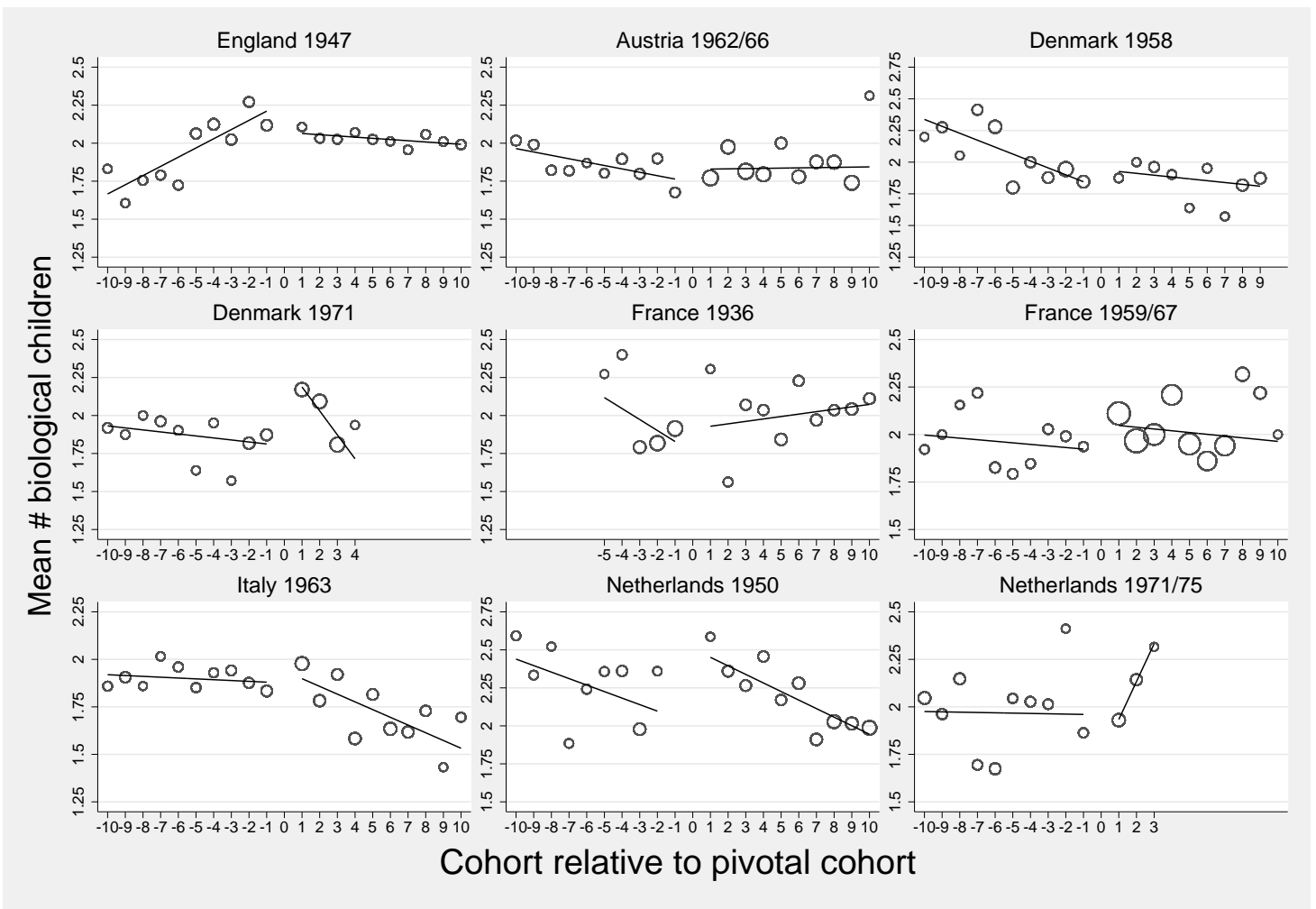

Figure A-2: Reduced forms by reform (\# biological children)

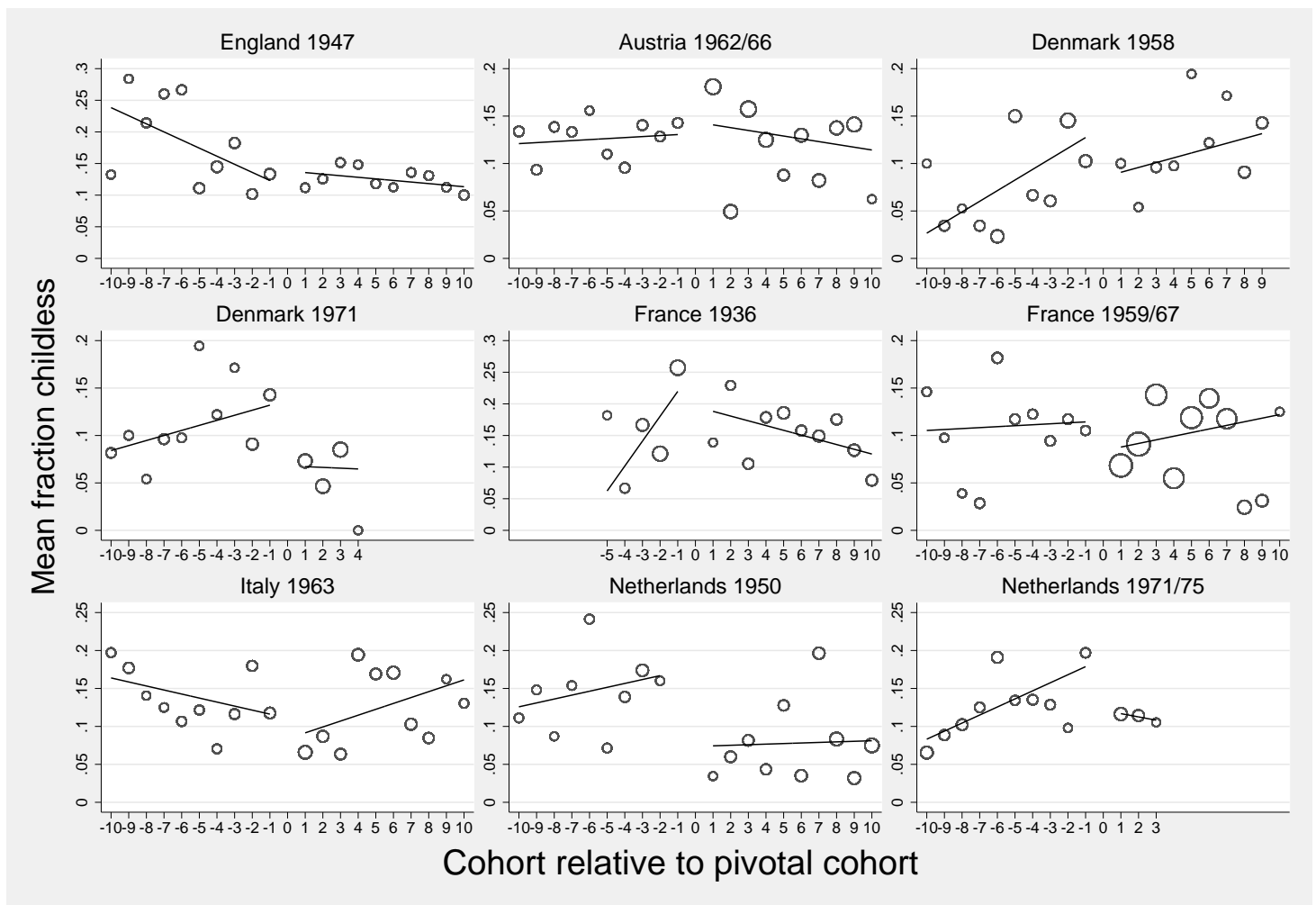

Figure A-3: Reduced forms by reform (childlessness) 